\author{
FEDERAL RESERVE BANK OF SAN FRANCISCO \\ WORKING PAPER SERIES
}

\title{
Nominal Interest Rates and the News
}

\author{
Michael D. Bauer \\ Federal Reserve Bank of San Francisco
}

January 2014

Working Paper 2011-20

http://www.frbsf.org/publications/economics/papers/2011/wp11-20bk.pdf

The views in this paper are solely the responsibility of the authors and should not be interpreted as reflecting the views of the Federal Reserve Bank of San Francisco or the Board of Governors of the Federal Reserve System. 


\title{
Nominal Interest Rates and the News*
}

\author{
Michael D. Bauer ${ }^{\dagger}$
}

January 16, 2014

\begin{abstract}
This paper provides new estimates of the impact of monetary policy actions and macroeconomic news on the term structure of nominal interest rates. The key novelty is to parsimoniously capture the impact of news on all interest rates using a simple no-arbitrage model. The different types of news are analyzed in a common framework by recognizing their heterogeneity, which allows for a systematic comparison of their effects. This approach leads to novel empirical findings: First, monetary policy causes a substantial amount of volatility in both short-term and long-term interest rates. Second, macroeconomic data surprises have small and mostly insignificant effects on the long end of the term structure. Third, the term-structure response to macroeconomic news is consistent with considerable interest-rate smoothing by the Federal Reserve. Fourth, monetary policy surprises are multidimensional while macroeconomic surprises are onedimensional.
\end{abstract}

Keywords: term structure of interest rates, no-arbitrage, news, monetary policy surprises, macroeconomic announcements, policy inertia

JEL Classifications: E43, E44, E52, G12

*This paper is based on my first dissertation chapter, "Revisions to Short-Rate Expectations: Policy Surprises and Macroeconomic News," which greatly benefited from the advice of my doctoral adviser James Hamilton. I also thank the editor, two anonymous referees, as well as Seth Carpenter, Michael Palumbo, Dimitris Politis, John Rogers, Irina Telyukova, Allan Timmermann, and Jonathan Wright, as well as participants at research seminars at the Federal Reserve Board, the Macroeconomics Seminar at UC San Diego, the 2011 Midwest Macroeconomics Meetings, the Missouri Economics Conference 2009, and the Northern Finance Association 2009 Conference. All errors are mine. The views expressed here do not necessarily represent those of others in the Federal Reserve System.

${ }^{\dagger}$ Federal Reserve Bank of San Francisco, michael.bauer@sf.frb.org 


\section{Introduction}

Monetary policy actions and macroeconomic news releases are major drivers of changes in financial asset prices. Knowledge of their impact on interest rates is of crucial interest to academics, policy-makers, and finance practitioners. To estimate it, studies typically resort to instrument-by-instrument event study regressions, where changes in various interest rates are separately regressed on a surprise measure. This is true for the literature studying the effects of monetary policy on financial markets as well as for the literature on macroeconomic announcement effects. ${ }^{1}$ Here I propose a novel methodology to study how new information affects the entire term structure of nominal interest rates. The movements and responses of all interest rates are modeled jointly, instead of considering individual securities separately. Moreover, both macroeconomic announcements and monetary policy surprises are incorporated in one common framework by recognizing the heterogeneity of news. This methodology is used to characterize and compare the impact of monetary policy actions and macroeconomic data surprises on interest rates. I find new results regarding the effects of monetary policy, the response of distant forward rates to macroeconomic news, and policy inertia. In addition, a crucial difference between economic news and policy news is documented: the former is one-dimensional, whereas the latter is multi-dimensional.

To jointly model the movements in all interest rates in response to news, I use a simple dynamic term structure model (DTSM) estimated on daily interest data for money market futures and Treasury yields. In this model, all interest rates are affine functions of a small number of underlying risk factors. This parsimonious representation facilitates the interpretation of the effects of news on a large number of interest rates and instruments. The risk factors are taken to be observable; they are the first three principal components of interest rates. By modeling these risk factors, we can understand how new information affects any interest rate, including those not included in the estimation. Three numbers - the changes in the risk factors - completely characterize the response of the entire term structure of interest rates to news about monetary policy or the economy.

The paper adds two methodological twists to the conventional affine DTSM. First, the model is estimated without making explicit the time-series dynamics of the risk factors. Be-

\footnotetext{
${ }^{1}$ Studies of monetary policy effects, following the seminal paper by Kuttner (2001), include Poole and Rasche (2000), Rigobon and Sack (2004), Bernanke and Kuttner (2005), Gürkaynak et al. (2005a), and Hamilton (2008). Among the numerous studies which explore the effects of macro announcements on financial markets are Fleming and Remolona (1997), Fleming and Remolona (1999), Balduzzi et al. (2001), Kearney and Lombra (2003), Gürkaynak et al. (2005b), Faust et al. (2007), Bartolini et al. (2008), and Rigobon and Sack (2008). Gürkaynak et al. (2005b) estimate the impact of both policy and macro surprises on long-term interest rates
} 
cause I do not calculate interest rate forecasts or term premium estimates, no time-series model is needed. I specify and estimate only the "cross-sectional dynamics," i.e., the relationship between risk factors and the cross section of interest rates. This is made possibly by the parameterization of Joslin et al. (2011), which results in a convenient separation of the likelihood function. Leaving aside the time-series model substantially reduces the number of free parameters, and avoids the statistical difficulties surrounding inference about highly persistent time series. ${ }^{2}$ The second methodological contribution is to explicitly account for heterogeneity of shocks to interest rates: Second moments of the factor shocks are allowed to depend on the type of news that occurs on a given day. This is a simple but effective way to integrate in a common framework the analysis of different types of news. It allows me to assess and compare the differential impact of policy actions and various types of macro news on interest rates.

How does monetary policy affect interest rates? I argue that it is useful to go beyond the event study regressions popularized by Kuttner (2001), and subsequently used by many others. In such regressions, changes in interest rates are used both as dependent and independent variables. This reveals the correlation of rates at different maturities around policy actions, but provides only limited insight into the causal impact of these policy actions on the term structure of interest rates. In fact, Kuttner-type event study results are implied by my model, because it captures the comovement of rates around policy actions. Such regressions suggest that monetary policy has much larger effects on the short end than on the long end of the term structure, but this simply reflects the fact that the comovement of interest rates declines with their distance in maturity. I propose to instead estimate and analyze the volatilities of interest rates, across maturities, that are caused by monetary policy. ${ }^{3}$ Focusing on this "term structure of volatility" shows that monetary policy generally has strong effects on the entire term structure. Policy-driven volatilities of long-term interest rates are just as high as those of short-term interest rates. ${ }^{4}$ The fact that the impact of monetary policy does not significantly decline with maturity suggests that the Fed has been successful in managing policy expectations and in affecting long-term rates.

The paper then turns to the effects of macroeconomic data releases on interest rates. First, I report the term structures of volatilities caused by macroeconomic news, documenting the

\footnotetext{
${ }^{2}$ Previous research-including Ang and Piazzesi (2003), Kim and Orphanides (2012), and Bauer et al. (2012) - has documented many issues with estimation of DTSMs due to the highly persistent nature of interest rates, all of which are avoided here.

${ }^{3}$ Kohn and Sack (2004) also consider policy-driven interest rate volatility, but they focus on a few selected instruments and do not compare policy and macro news.

${ }^{4}$ These findings are confirmed to be robust to the use of tight event windows around policy announcements using intradaily data.
} 
different levels and shapes of volatilities across news releases. ${ }^{5}$ Then I present and discuss the "term structure of announcement effects," i.e., the response of various interest rates to macroeconomic data surprises. In this context I revisit the question posed by Gürkaynak et al. (2005b) whether data surprises cause significant shifts in the long end of the term structure, i.e., whether they have level effects. These authors find that long-term forward rates show strong responses to some important economic releases. In contrast, I estimate announcement effects for the long end of the term structure that are mostly insignificant or only marginally significant, and in those cases where the effects are statistically significant, the magnitudes are too small to be economically meaningful. Even the arguably most important macroeconomic data release, the nonfarm payroll number, has essentially no effect on distant forward rates. Incorporating information from the entire term structure evidently is important in this context, and explains the difference in results. While Gürkaynak et al. (2005b) conclude from their evidence that long-run expectations of economic agents are time-varying, my results suggest that stable long-run expectations are not at odds with the data.

The analysis also has implications for monetary policy inertia and interest-rate smoothing. Macroeconomic surprises lead to revisions of short-rate expectations that reflect an anticipation of incremental changes of the policy rate in the same direction, hence market participants appear to expect an inertial response of monetary policy to changes in fundamentals. I revisit evidence in Rudebusch (2006) to assess the degree of interest-rate smoothing on the part of the Fed, and find that a considerable amount of interest-rate smoothing is consistent with near-term forward rate responses to macro news. Based on my results it is not implausible for the Fed to put up to $50 \%$ weight on last quarter's value of the policy rate when adjusting it toward a new desired target level. This finding stands in contrast to the results in Rudebusch (2002) and Rudebusch (2006), who argues that policy inertia is caused not by an intrinsic smoothing motive of the central bank but by autocorrelated policy shocks.

The econometric framework allows me to systematically compare the effects of policy surprises and macroeconomic news on interest rates. The results reveal an important difference between monetary policy actions and macroeconomic data surprises. While the volatility caused policy and macro news is similar, the comovement of different interest rates is very different. Policy news are inherently multi-dimensional in their impact on the term structure: the effects are sufficiently varied that at least two factors are needed to capture the response of interest rates across maturities. On the other hand macroeconomic news are one-dimensional: For a given type of macro announcement, the term structure shifts in a similar fashion, i.e., one

\footnotetext{
${ }^{5}$ Jones et al. (1998) also analyze volatility of interest rates in response to macroeconomic news, but focus on only a small number of long-term yields and do not systematically consider the effects across maturities.
} 
factor is sufficient to capture the response across maturities. The economic intuition behind this result is that the Federal Reserve surprises markets along more than one dimension, using communication in addition to decisions about the policy rate as independent monetary policy tools. ${ }^{6}$

The paper is structured as follows: Section 2 describes the specification and estimation of the no-arbitrage model. Section 3 presents results about the effects of monetary policy on the term structure. In Section 4 I estimate the effects of macroeconomic data surprises, with a focus on the sensitivity of long forward rates, and provide new results about policy inertia. Section 5 presents test results that compare the effects of monetary policy news and macroeconomic news. Section 6 concludes.

\section{Modeling news and term structure movements}

This section presents a simple model to parsimoniously capture movements in various interest rates in response to different types of news, and discusses the data and estimation of the model.

\subsection{Affine model for the cross section of interest rates}

A DTSM can parsimoniously capture movements in many different interest rates using only a small number of risk factors. Here, an affine model is used, in which interest rates are linear functions of these factors (Duffie and Kan, 1996). Denote the $N$-vector of risk factors by $\mathcal{P}_{t}$, which contains the information available to investors at time $t . \mathcal{P}_{t}$ evolves according to a first-order vector autoregression (VAR) under the risk-neutral probability measure:

$$
\mathcal{P}_{t+1}=\mu+\Phi \mathcal{P}_{t}+u_{t+1}
$$

The innovations $u_{t}$ are Gaussian, serially uncorrelated, and for now assumed to be homoskedastic with variance-covariance matrix $\Omega$-this assumption will be relaxed below to allow for heteroskedasticity. Denote the rate for an overnight default-free loan between days $t$ and $t+1$,

\footnotetext{
${ }^{6}$ This finding is related to the work of Gürkaynak et al. (2005a), who use principal component analysis to show that more than one factor is needed to describe monetary policy actions.
} 
the short rate, by $r_{t}{ }^{7}$ It is an affine function of the risk factors, i.e.,

$$
r_{t}=\delta_{0}+\delta_{1}^{\prime} \mathcal{P}_{t}
$$

Under these assumptions, interest rates are affine functions of $\mathcal{P}_{t}$. The yield on a zero coupon bond with remaining maturity $n$ is $y_{t}^{n}=A_{n}+B_{n}{ }^{\prime} \mathcal{P}_{t}$. For a one-period forward rate for a loan from $t+n$ to $t+n+1$, I write $f_{t}^{n}=A_{n}^{f}+B_{n}^{f^{\prime}} \mathcal{P}_{t}$. The loadings are given in Appendix A.

Under the risk-neutral probability measure, financial assets can be priced as discounted expected values of future payoffs, as if investors were risk-neutral. Of course, investors are not risk-neutral and asset prices are affected by both expectations of future fundamentals and risk premia. To disentangle these two components, one would need to specify the dynamics of the risk factors under the real-world probability measure. Since the goal here is not to estimate risk premia but instead to parsimoniously capture the cross section of interest rates, I do not specify or estimate the real-world dynamics of interest rates. This has the advantage of avoiding the statistical difficulties involved in estimating the time-series properties of interest rates due to their high persistence (Kim and Orphanides, 2012; Bauer et al., 2012).

Assuming absence of arbitrage leads to a parsimonious factor structure for interest rates. Why is the no-arbitrage assumption useful? An alternative would be a factor model, where loadings of interest rates on the risk factors are unrestricted. However, the no-arbitrage model has several advantages. It parsimoniously captures the revision of (risk-adjusted) expectations of the entire path of future short rates on a given day $t$ :

$$
\mathcal{R}_{t}=\left\{\left(E_{t}-E_{t-1}\right) r_{t+n}\right\}_{n=0}^{\infty}
$$

The revision $\mathcal{R}_{t}$ captures the effects of new information on the term structure of interest rates. Note that it reflects expectations under the risk-neutral measure, so it includes both changes to real-world expectations of future short rates and changes in term premia- in the remainder of the text, "expectations" (and the expectations operator $E$ ) should be understood to refer to expectations under the risk-neutral measure. ${ }^{8}$ The infinite-dimensional object $\mathcal{R}_{t}$ is captured by just $N$ numbers using the model. ${ }^{9}$ Focusing on $\mathcal{R}_{t}$ helps to understand how news affect

\footnotetext{
${ }^{7}$ I abstract from the facts that the policy rate in the U.S., the effective fed funds rate, deviates from the target set by the monetary authority, and that the target has a step-function character. Both simplifications are inconsequential since I do not include observations of the short rate.

${ }^{8}$ Generally, $\mathcal{R}_{t}$ is understood to capture "news" in the sense that changes are unexpected before $t$. Since changes in term premia can have a predictable component, this is not literally true. However, at the daily frequency this predictable component is negligibly small, see for example Hamilton (2009) — daily interest rate changes are mostly driven by news and essentially unpredictable.

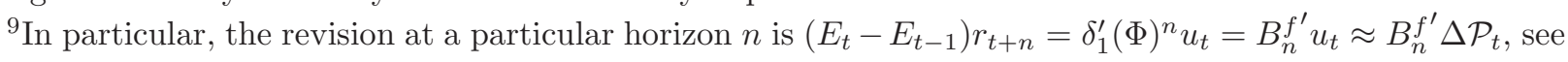


different parts of the term structure of interest rates, and how these effects interact. Daily changes in yields reflect the average revision over the maturity of the bond, while changes in forward rates reflect the revision of expectations at a specific horizon. Notably, movements and responses of any interest rate can be analyzed, whether it is included in the estimation or not. We can analyze, for example, the response of distant-horizon forward rates to macroeconomic news, which will be done in Section 4. Importantly, information from the entire term structure of interest rates is brought to bear on such questions, instead of just one observed interest rate. Consequently, idiosyncratic noise is less of an issue. An additional advantage is that a no-arbitrage model puts tight parametric restrictions on the loadings of interest rates on risk factors, which improves estimation efficiency.

\subsection{Data}

The data used in estimating the model are daily observations of money market futures rates and Treasury yields, from January 1990 to December 2009. I include futures rates in the analysis because market participants and academics alike often consider changes in money market futures to assess the effects of policy and macro news on the term structure. Specifically, Kuttner (2001) uses fed funds futures to estimate the impact of policy actions on the term structure, and I will revisit his evidence in the context of my model. The futures data here comes from Bloomberg and includes both federal funds futures and Eurodollar futures. I include fed funds futures contracts that settle based on the fed funds rate over the subsequent four months, denoted by FF1 to FF4, and Eurodollar futures contracts that settle based on the LIBOR rate at the end of the next quarter up to fourteen quarters in the future, denoted by ED2 to ED15. For details on the pricing of money market futures using the affine model refer to Appendix C. The yield data consists of unsmoothed zero-coupon rates constructed from observed bond yields and includes maturities of $6,12,18$ months and 2 to 10 years. ${ }^{10}$

The choice of instruments is motivated by the desire to include sufficient information about both the short end and the long end of the term structure of interest rates. While money market futures reflect investor expectations over short and medium horizons, bond yields are needed to cover longer maturities. As in most studies using models of the term structure, the short rate itself, the federal funds rate, is not included, for two reasons: First, its step-function character make it difficult to model it accurately. Second, it is not needed,

Appendix B. This is simply a linear combination of the shocks, with the weights depending on the horizon. The approximation, which is accurate because $\mathcal{P}_{t}$ is extremely persistent under the risk-neutral measure, simplifies the implementation further, since we don't need to estimate the shocks $u_{t}$.

${ }^{10}$ I thank Anh Le of the University of North Carolina for providing this data. 
in addition to the included instruments, to pin down the short end of the term structure.

\subsection{Estimation}

The model-implied rates for all instruments at time $t$ are denoted by vector $Y_{t}$, which has $J=30$ elements, and the vector of observed rates is $\tilde{Y}_{t}$. From the affine model we have $Y_{t}=A+B^{\prime} \mathcal{P}_{t}$, where the $J$-vector $A$ and the $N \times J$ matrix $B$ contain the model-implied loadings of futures rates and yields on the risk factors. I use the convenient canonical form of Joslin et al. (2011, henceforth JSZ), assuming that $N$ linear combinations of $Y_{t}$ are priced without error. Under this normalization, $A$ depends on the long-run mean of the short rate, on the eigenvalues of $\Phi$, denoted by $\lambda$, and on the second moments of the shocks, while $B$ depends only on $\lambda .{ }^{11}$ The risk factors are taken to be the first three principal components of $\tilde{Y}_{t}$. The choice $N=3$ is based on the common finding that three factors explain almost all of the the cross-sectional variation in interest rates (Litterman and Scheinkman, 1991).

I deviate from common practice in the term structure literature by using interest rate changes, instead of levels, for estimation. Rate changes are given by $\Delta Y_{t}=B^{\prime} \Delta \mathcal{P}_{t}$. The intercept drops out, and the loadings are completely determined by $\lambda$. The measurement equation is specified as

$$
\Delta \tilde{Y}_{t}=B^{\prime} \Delta \mathcal{P}_{t}+w_{t}
$$

where $w_{t}$ is a $J \times 1$ measurement error that is Gaussian white noise and has variance-covariance matrix $\sigma_{w}^{2} I_{J} \cdot{ }^{12}$ Given (4) and the unspecified time series process for $\mathcal{P}_{t}$, the conditional likelihood function of the observed yield changes is

$$
f\left(\Delta \tilde{Y}_{t} \mid \Delta \tilde{Y}_{t-1} ; \theta\right)=g\left(\Delta \tilde{Y}_{t} \mid \Delta \mathcal{P}_{t} ; \lambda, \sigma_{w}^{2}\right) \times h\left(\Delta \mathcal{P}_{t} \mid \Delta \mathcal{P}_{t-1}, \ldots ; \gamma\right)
$$

where $\gamma$ denotes the parameters determining the real-world-measure dynamics time series behavior of $\mathcal{P}_{t}$, and $\theta=\left(\gamma^{\prime}, \lambda^{\prime}, \sigma_{w}^{2}\right)^{\prime}$. The likelihood function is equal to the product of two terms: The first term captures the cross-sectional fit, while the second term captures the time-series fit, and the two terms do not share any parameters. This separation is due to the way that JSZ impose the normalizing restrictions on their canonical form. ${ }^{13}$ As a result, the ML estimates of $\lambda$ and $\sigma_{w}^{2}$ can be obtained by simply maximizing the "cross-sectional

\footnotetext{
${ }^{11}$ This notation ignores that the intercept is time-varying due to variation in convexity.

${ }^{12}$ This measurement specification implies that observed interest rates contain a random walk under the real-world measure. Because the time series dimension of the data is ignored, this is unproblematic.

${ }^{13}$ Because JSZ consider yield levels, which contain convexity, the shock covariance matrix appears in both the terms. When using interest rate changes, however, the intercept $A$ drops out, and the separation is complete in the sense that shock covariances do not appear in the cross-sectional likelihood.
} 
log-likelihood," i.e., $\sum_{t=1}^{T} \log g\left(\Delta \tilde{Y}_{t} \mid \Delta \mathcal{P}_{t} ; \lambda, \sigma_{w}^{2}\right)$. Estimation of the cross-sectional parameters $\lambda$ and $\sigma_{w}$ is possible without an explicit time-series model for $\mathcal{P}_{t}$. This circumvents the usual problems surrounding DTSM estimation, due to the weak identification of the time-series dynamics of interest rates, which are highly persistent. Avoiding the estimation of a timeseries model drastically simplifies estimation.

Parameter estimates are obtained by numerically maximizing the (cross-sectional) loglikelihood. I first estimate the model by assuming that $\lambda$ contains real distinct eigenvalues. The results (not shown) suggest that one eigenvalue should be restricted to unity and the other two eigenvalues set equal to each other. Imposing these restrictions leaves the optimal value of the likelihood function essentially unchanged, i.e., they are not rejected by a likelihood-ratio test. Therefore I proceed with this restricted version of the model. ${ }^{14}$ This cross-sectional specification exactly parallels the arbitrage-free Nelson-Siegel model of Christensen et al. (2011). Notably, under this specification, only one parameter determines the cross-sectional dynamics of the term structure. This parameter, the repeated eigenvalue, is estimated to be 0.997356 , with standard error $5.4 \cdot 10^{-5}$. Just as the usual Nelson-Siegel parameter in, for example, Christensen et al. (2011), this parameter captures the horizon at which hump-shaped term structure movements typically have their peak.

How well does this extremely parsimonious term structure model fit futures and yield changes? The root-mean-squared error is 1.98 bps (basis points), compared to a standard deviation of actual rate changes of $6.72 \mathrm{bps}$. An $R^{2}$-type measure of fit, calculated as one minus the ratio of pricing error variance to the variance of rate changes, is equal to $91.3 \%$. The fit is surprisingly good, specifically in light of two observations: First, rate changes are harder to fit than levels, in the sense that idiosyncratic movements are more pronounced, relative to the total variability. Therefore one should not compare the fit here to, for example, the explanatory power of the first three principal components for interest rate levels (which in the data set used here is $99.6 \%$ ). Second, the model is used to simultaneously fit fed funds futures, Eurodollar futures, and Treasury yields. Overall, the accurate fit obtained using this highly parsimonious model can be considered an empirical success.

\subsection{Heterogeneity of news}

To integrate different sources of news and their effects on the term structure of interest rates in one common framework, I now introduce a simple extension into the conventional Gaussian

\footnotetext{
${ }^{14}$ These restrictions imply that the normalized pricing factors $X_{t}$, the factors in the rotated model in which the JSZ normalizations are imposed, i.e., the "Jordan-normalized" factors in the language of JSZ, can be labeled as level, slope, and curvature.
} 
affine model. The starting point is the assumption that for daily interest rate data, we can classify each day reasonably well according to the type of news that occur on that day. For each category of news, the covariance matrix of the shocks is allowed to differ. This simple deterministic heterogeneity recognizes differences in the volatility and correlations of interest rates, depending on which type of news drive the term structure. Formally, $u_{t} \sim$ $N\left(0, \Omega_{l(t)}\right)$ where $l(t)$ maps each calendar day into one of $L$ categories of news, or "variance regimes." Note that this assumption differs from that made in regime-switching term structure models (Bansal and Zhou, 2002; Monfort and Pegoraro, 2007), where the state variable that determines the regime is stochastic and unobservable (here, the state $j(t)$ is observable), and from models where volatility is stochastic. The process is still affine, because the timedependence of the covariance matrix is deterministic. ${ }^{15}$ The affine loadings and the crosssectional likelihood function remain completely unaffected. ${ }^{16}$

The analysis will use five news regimes:

1. Days with policy actions by the Federal Open Market Committee (FOMC). Until December 2004 these are identified by Gürkaynak et al. (2005a), and for the remainder of the sample I use the days when the FOMC statement was released (148 days total). ${ }^{17}$

2. Days on which the BLS releases its employment report (223 days).

3. Days with a release of either the Consumer Price Index (CPI) or the Producer Price Index (PPI) (344 days).

4. Days with new retail sales numbers (126 days).

5. All other days.

Days that would fall into more than one of the categories 1-4 are excluded. The category "all other days" can be understood to represent days without major policy or macro news. This is obviously only a rough approximation, given the vast amount of possibly market-relevant

\footnotetext{
${ }^{15}$ Under the assumption of observable variance regimes, the conditional moment-generating function of $\mathcal{P}_{t}$ is given by

$$
E_{t}\left(\exp \left(u^{\prime} \mathcal{P}_{t+1}\right)\right)=\exp \left(u^{\prime} \mu+.5 u^{\prime} \Omega_{j(t)} u+u^{\prime} \Phi \mathcal{P}_{t}\right)
$$

which is exponentially affine in $\mathcal{P}_{t}$. Therefore $\mathcal{P}_{t}$ is still an affine Markov process, as defined in, for example, Singleton (2006, p. 101).

${ }^{16} \mathrm{~A}$ subtle issue is that a bond's convexity is now time-varying. It is safe to ignore this issue: daily changes in convexity are very small, because the maturity barely changes.

${ }^{17}$ The choice of policy events is similar to that in several other papers, including, for example, Nakamura and Steinsson (2013). As in most papers studying Federal Reserve policy announcements, days with speeches by FOMC members are not included - these are very frequent and do not typically dominate the news on a given day.
} 
news. However, I have found that defining this regime more narrowly by also excluding days with other macroeconomic announcements (such as GDP releases and various others) does not affect the results, so this approximation seems defensible.

Why these five regimes? They were chosen to investigate how policy actions and news about the employment situation, about inflation, and about aggregate demand differ in their impact on the yield curve. One could easily allow for more regimes, to analyze the effects of other macroeconomic data releases on interest rates. Here, a small number of important news categories is sufficient to demonstrate some important systematic differences between days with policy new and major macroeconomic news.

Naturally multiple pieces of news may affect asset prices on any given day. Therefore the approach suggested here is imperfect. This is not as problematic as it seems. Some releases typically dominate all other pieces of news, such as the payroll, CPI, or retail sales numbers. Grouping these days into different categories provides some insight into the effects of these sources of news. Moreover, if there are separate macro releases on the same day, it is still possible to separately estimate their impact in a multivariate regression. In general, simplicity and effectiveness lend substantial appeal to my approach of categorizing days into subsamples according to which type of news likely drove interest rate changes on a given day.

The covariance matrices $\Omega_{1}, \ldots, \Omega_{L}$ do not appear in the cross-sectional likelihood function, and therefore need to be estimated separately. This can be done in a straight-forward fashion, using sample covariance matrices for each category of news. For regime $l, \Omega_{l}$ is the covariance matrix of the shocks $u_{t}$. Because the risk factors are highly persistent, $u_{t} \approx \Delta \mathcal{P}_{t}$, and we can simply take the sample covariance matrices of the changes in the term structure factors, separately estimated for the sub-sample of days corresponding to each news regime.

\section{The Impact of Monetary Policy Actions}

This section addresses the question how monetary policy actions affect the term structure of interest rates. After discussing terminology and considering some specific policy actions and their impact, I first revisit the event study regressions used by Kuttner (2001) and many after him, and then propose an alternative perspective based on policy-driven volatilities.

\subsection{Policy surprises}

The object of interest is the revision of the expected path of short rates due to a policy

action. This is what I term a "policy surprise," in contrast to some other authors who 
have used this term to denote the changes in interest rates only at the short end of the term structure (Kuttner, 2001; Rigobon and Sack, 2004; Bernanke and Kuttner, 2005). ${ }^{18}$ The definition here seems more natural since it pertains to the entire term structure, capturing monetary policy actions more broadly. The model implies a parsimonious representation of the infinite-dimensional object $\mathcal{R}_{t}$. Based on the estimate of $\mathcal{R}_{t}$, one can describe movements in any desired interest rate and expectations at any horizon. In this sense, $\mathcal{R}_{t}$ provides a complete description of the impact of a monetary policy action on the term structure of interest rates.

Figure 1 exemplifies the impact of policy actions on the term structure of interest rates, by showing changes in actual $\left(\Delta \tilde{Y}_{t}\right)$ and fitted interest rates $\left(\Delta Y_{t}\right)$, as well as the estimated revision $\mathcal{R}_{t}$, on two specific days. The top row shows the effects on interest rates of the FOMC statement on 22 March 2005. On this day the Committee decided to increase the target for the federal funds rate by 25 bps, which had been expected and did not cause near-term fed funds futures to move. However, the FOMC also included more hawkish language in the statement, specifically that "pressures on inflation have picked up in recent months." This change in the language surprised market participants, who revised upward their expectations of the future path of the policy rate. The bottom row shows rate changes for 1 December 2008, when Chairman Ben Bernanke gave a speech declaring that the Fed was likely to "purchase longerterm Treasury securities [...] in substantial quantities." This announcement of unconventional monetary policy through large-scale asset purchases led to significant decreases in interest rates across the maturity spectrum through a combination of lower expected short rates and lower risk premia. ${ }^{19}$

These examples demonstrate three important issues. First, changes in the federal funds target clearly are not a useful measure of monetary policy actions - on March 22, 2005, the target rate was decreased but long rates increased, and on December 1, 2008, it was left unchanged yet long rates fell. This is the main point made by Kuttner (2001). Second, changes in near-term fed funds futures contracts are not a sufficient measure either. Near-term fed funds futures rates remained essentially unchanged in both instances. This is what prompted Gürkaynak et al. (2005a) to construct a second surprise measure, beyond the Kuttner surprise, to capture information from changes in Eurodollar futures rates. Third, to accurately understand the policy surprise, one needs to capture the entire revision of short-rate expectations. Even knowledge of the movements in several futures rates, and of the implied "target" and

\footnotetext{
${ }^{18}$ The difference between a policy surprise and a policy shock is that while both are unanticipated, the latter is also exogenous. Since changes in interest rates caused by policy actions may be endogenous to the current economic situation, the term "surprise" is more accurate here.

${ }^{19}$ A quickly growing literature has evolved around the potential effects of such unconventional monetary policy, with differing answers as to the importance of changes in expectations and risk premia for the actually observed changes in long-term interest rates (Bauer and Rudebusch, 2013; Gagnon et al., 2011).
} 
"path" factors of Gürkaynak et al. (2005a) does not provide a sufficiently accurate picture of the effects of policy surprises on interest rates. In contrast, $\mathcal{R}_{t}$ appropriately measures the entire monetary policy surprise.

\subsection{Revisiting Kuttner regressions}

In an important paper, Kuttner (2001) introduced a new approach to estimate the impact of monetary policy on asset prices. In these regressions the dependent variable is the change in an asset price or interest rate around policy announcements, and the independent variable is based on the rate change in a near-term money market futures contract. The observations are daily or intradaily changes around the announcements. Kuttner used a surprise measure based on the change in rate of the spot-month fed funds contract, scaled to account for the fact that settlement is based on the average fed funds rate over that month. Other authors have used the one-month-ahead fed funds futures contract (Poole and Rasche, 2000) or the nearest Eurodollar futures contract (Rigobon and Sack, 2004). In either case, the independent variable is intended to measure the monetary policy surprise, and regression coefficients and $R^{2}$ are interpreted as measuring the impact of the monetary policy action on asset prices.

I revisit these regressions in the context of the term structure model of this paper. Because the model implies second moments for rate changes, it also implies regression coefficients and $R^{2}$ for the Kuttner regressions. For the regression of the change in a yield with maturity $n$ on the change in the FF1 rate, the model-implied regression coefficient is given by

$$
\beta=\frac{\operatorname{Cov}\left(\Delta y_{t}^{n}, \Delta F F_{t}^{(1)}\right)}{\operatorname{Var}\left(\Delta F F_{t}^{(1)}\right)}=\frac{\operatorname{Cov}\left(B_{n}^{\prime} \Delta \mathcal{P}_{t}, B_{F F 1}^{\prime} \Delta \mathcal{P}_{t}\right)}{\operatorname{Var}\left(B_{F F 1}^{\prime} \Delta \mathcal{P}_{t}\right)+\sigma_{w}^{2}}=\frac{B_{n}^{\prime} \operatorname{Var}\left(\Delta \mathcal{P}_{t}\right) B_{F F 1}}{B_{F F 1}^{\prime} \operatorname{Var}\left(\Delta \mathcal{P}_{t}\right) B_{F F 1}+\sigma_{w}^{2}},
$$

and the coefficient of determination is

$$
R^{2}=\frac{\left[\operatorname{Cov}\left(\Delta y_{t}^{n}, \Delta F F_{t}^{(1)}\right)\right]^{2}}{\operatorname{Var}\left(\Delta y_{t}^{n}\right) \operatorname{Var}\left(\Delta F F_{t}^{(1)}\right)}=\frac{\left[B_{n}^{\prime} \operatorname{Var}\left(\Delta \mathcal{P}_{t}\right) B_{F F 1}\right]^{2}}{\left(B_{n}^{\prime} \operatorname{Var}\left(\Delta \mathcal{P}_{t}\right) B_{n}+\sigma_{w}^{2}\right)\left(B_{F F 1}^{\prime} \operatorname{Var}\left(\Delta \mathcal{P}_{t}\right) B_{F F 1}+\sigma_{w}^{2}\right)}
$$

For regressions of changes in Eurodollar futures rates, the loadings $B_{n}$ are replaced by $B_{E D i}$. The model implies values for the loadings, for $\sigma_{w}^{2}$, and for $\operatorname{Var}\left(\Delta \mathcal{P}_{t}\right) \approx \Omega_{1}$. I estimate the regressions for changes in Eurodollar futures rates and changes in yields, using the change in the one-month-ahead fed funds futures rate (FF1) as the policy surprise (as in Poole and Rasche, 2000). The estimation sample consists of the days in regime 1.

Figure 2 shows the actual and model-implied regression results, for Eurodollar futures in the left panel, and for yields in the right panel. The model accurately replicates the results 
of these regressions: the model-implied coefficients (solid lines) are generally very close to the actual regression coefficients and always within the 95\%-confidence intervals (error bands). The $R^{2}$ implied by the model (crosses) also accord very well with the empirical $R^{2}$ (circles). Evidently, the results of Kuttner-style regressions can be captured and replicated by a simple term structure model which accounts for the covariance of interest rates on days with monetary policy actions.

The graph shows that regression coefficients and $R^{2}$ quickly decrease with maturity, in line with the findings in Kuttner's original paper and in subsequent studies. It reflects the fact that the comovement of long-term interest rates with a given short-term interest rate declines with maturity. This, however, should not lead to the interpretation that monetary policy barely affects the long end of the term structure. This interpretation would rest on a narrow definition of monetary policy actions, namely one that involves only changes in short-term interest rates. Such a definition is too narrow because policy can affect longterm rates through communication, and more recently through explicit forward guidance and balance sheet policies. Regressions in the Kuttner tradition estimate the impact of only a very specific, narrowly defined type of policy surprise on interest rates. Including the path factor of Gürkaynak et al. (2005a) expands the type of policy surprises that are captured to some degree, but still only measures those surprises that affect interest rates at short and medium maturities.

\subsection{Volatility caused by monetary policy}

An alternative approach for learning about the financial market effects of monetary policy is to consider asset price volatilities caused by policy actions. While some other studiesfor example, Kohn and Sack (2004)-have followed this approach, the novelty here is that the entire term structure of policy-driven volatilities is estimated and analyzed, so that we can say something about the effects of monetary policy across maturities. Furthermore, the empirical framework integrates both policy and macro news, so that we can compare different drivers of volatility. Figure 3 shows estimated volatilities for changes in Eurodollar futures (top row), yields (middle row), risk-adjusted short-rate expectations/forward rates (bottom row). Each column corresponds to one of the five news regimes, and the left-most column displays volatilities due to FOMC policy actions.

With regard to the overall level of the volatility term structures, monetary policy actions are clearly a major source of interest rate volatility: First, the volatilities associated with policy news are comparable in magnitude to those due to macro news releases. Second, the volatilities are higher on days with policy news than on those days without any major policy 
or macro news (regime 5). In Section 5, I investigate the differences in second moments across regimes more formally, and these two observations are confirmed using Bartlett tests for equal variance. The conclusion is that volatilities due to monetary policy news are substantial, in line with economic intuition and the abundant anecdotal evidence about the important role of monetary policy for financial markets. Notably, much of the information released in FOMC statements is typically anticipated by market participants. The results here show that there still is a lot of new information on policy days, causing a significant amount of action in fixed income markets.

Turning to the specific shape of the term structure of volatility associated with monetary policy news, it is evident that policy actions create substantial volatility in short-term interest rates. The policy-driven volatility curve is flatter and less hump-shaped than those in the other news regimes. Specifically, on policy days the volatility of short-term rates is at least as high as the volatility of long-term rates, whereas on days with macro news, short-term volatilities are much smaller than long-term volatilities. Since the Fed often surprises market participants with its choice of the policy rate target, as evidenced by Kuttner (2001), it causes volatility at the short end of the term structure.

Can policy affect long-term interest rates? Notably, policy actions cause volatilities in long-term rates that are just as large as the volatilities in short-term rates. Appendix D shows the robustness of this result to the use of intraday changes instead of daily changes. Evidently, the Fed not only affects short-term interest rates but also causes similarly large movements in long-term interest rates.

This result contrasts with the conclusion in other studies that the impact of monetary policy declines with maturity, which are based on event study regressions - see Kuttner (2001), Gürkaynak et al. (2005a), and others. The reason is that these studies essentially estimate the correlations of changes in different interest rates, which naturally decline with the distance in maturities, whereas I estimate the policy-driven volatilities, which remain high even at the long end of the term structure.

\subsection{The bottom line: monetary policy and interest rates}

This section addressed two important questions related to the interaction of monetary policy and interest rates. The first question is, "What is a good measure of the policy surprise?" My answer is, as argued above, that the right measure is the revision $\mathcal{R}_{t}$, because it captures the entire policy surprise instead of specific interest rates. I argue that alternative measures, such as the Kuttner surprise, the change in a near-term Eurodollar futures rate (as in, for example, Rigobon and Sack, 2004), or the target and path surprises constructed by Gürkaynak et al. 
(2005a), are insufficient because they focus only on one part of the term structure. To parsimoniously capture the revision, which is an infinite-dimensional object, a term structure model is required.

The second question is, "What is the impact of policy surprises on the term structure of interest rates?" This question is more difficult to answer because we generally do not have an independent measure of the policy action (as in the case of macroeconomic announcements). The commonly used surprise measures - the Kuttner surprise or the target and path surprises of Gürkaynak et al. (2005a) — are themselves based on changes in interest rates, and the common regression approach amounts to estimating comovement of rates at different maturities. I propose to instead consider the term structure of interest rate volatilities that are caused by monetary policy actions. Of course, this approach cannot answer the question by how much a given policy action affects long-term interest rates. This question can only be answered for a narrowly defined and clearly quantifiable policy action. However, monetary policy has many dimensions, due to the reliance of central banks on different instruments including communication. The approach here captures how various policy actions, taken together, affect the term structure of interest rates, which is a new and useful perspective on the financial market effects of monetary policy.

\section{The Impact of Macroeconomic News}

This section analyzes the impact of new information in macroeconomic data releases on the term structure of interest rates. My affine model can improve over the instrument-byinstrument regressions common in this literature, by incorporating all available information across instruments in one econometric framework. This leads to new evidence on the impact of macro news on far-ahead forward rates and on monetary policy inertia.

\subsection{Macroeconomic data surprises}

Releases of macroeconomic data are an important source of new information to market participants. Asset prices respond to the surprise component of a release, i.e., the difference between the released number and the market's consensus expectation. To estimate the expected value, I follow common practice and use the median of the forecasts compiled by Money Market Services to proxy for the average market participant's expectation. ${ }^{20}$ Macroeconomic data

\footnotetext{
${ }^{20}$ Such survey-based expectations can suffer from measurement error, as argued for example by Rigobon and Sack (2008).
} 
surprises constructed in this way have been well documented to have significant effects on asset prices including interest rates.

To understand the impact of macroeconomic data surprises on interest rates, it is useful to first consider some specific examples. One of the most closely watched economic data releases is the employment report of the Bureau of Labor Statistics (BLS). The surprise component in nonfarm payroll employment typically has strong effects on asset prices (see, for example, Gürkaynak et al., 2005b). Figure 4 shows the effects of two specific releases on the nominal term structure, i.e., on Eurodollar futures rates, yields, and on the expected policy path. The top row visualizes what happened on June 5, 2009. The released payrolls number for May was $-345,000$, while markets had anticipated $-500,000$. Despite the large decrease in employment, this was good news. Interest rates because the more optimistic outlook on the economy raised expectations of future policy rates. The bottom row of the figure shows changes for July 2, 2004. The released number for June was 112,000, which was a solid increase in employment but fell far short of the consensus expectation of 230,000. The bad news, leading to expectations of looser monetary policy, manifested itself in decreasing interest rates across maturities. These two releases exemplify the typical impact of the release of a procyclical economic indicator on the term structure of interest rates.

\subsection{Volatility caused by macroeconomic news}

News-specific volatilities provide a useful perspective on the impact of macro news on interest rates. ${ }^{21}$ Figure 3 shows the term structures of volatility for each type of news. The magnitudes of the volatilities for days with key macro data releases confirm the well-known fact that macroeconomic announcements are major drivers of interest rates (see, for example Fleming and Remolona, 1997).

The term structures of volatility in Figure 3 show that the most important driver of interest rates is the BLS employment report. On the days of its release, interest rate volatility is about 40-60\% higher than on other days. The employment report and more specifically the payrolls number (as evidenced below), dominates all other releases in terms of information content and causes the strongest revisions of the assessment of the current economic situation and of expectations of monetary policy by market participants. New information about the labor market is the biggest source of interest rate volatility, more important than news about monetary policy, the price level, or aggregate demand.

\footnotetext{
${ }^{21}$ Jones et al. (1998) analyze volatility of long-term Treasury yields in response to macroeconomic news. In contrast, the following provides a joint analysis of volatilities and responses of all interest rates across maturities.
} 


\subsection{Announcement effects}

Event study regressions for estimating macroeconomic announcement effects were made popular by Balduzzi et al. (2001) and now dominate this literature. Changes in yields or other asset prices are regressed on the surprise components in macroeconomic data releases. The surprise measures are obtained using survey-based expectations, and then standardized to make regression coefficients comparable across releases. The various surprises are included in a multivariate regression in order to partial out the effects of releases that occur on the same day. For every interest rate or asset price included in the analysis, a separate regression is carried out. $^{22}$

Instead of estimating the impact of macro announcements on the term structure as a whole, the common approach separately estimates the impact on various securities. Thus, the cross-sectional restrictions that are implied by absence of arbitrage are ignored. ${ }^{23}$ This is unsatisfactory for several reasons: First, we cannot say anything about instruments or maturities that are not included in the regression analysis. Second, ignoring cross-sectional restrictions gives up potential gains in estimation efficiency. Third, to understand whether there are level or slope effects of particular macro releases, one should incorporate the whole term structure in the estimation instead of making conclusions based on some specific maturities.

The model in this paper allows me to estimate the impact of macroeconomic news on the entire term structure. To do so, I first estimate the response of the risk factors $\mathcal{P}_{t}$ to the macro surprises using seemingly unrelated regressions (SUR, see Zellner, 1962). This results in three regression coefficients for each macro announcement series - the responses of the risk factors to a one standard deviation surprise in each release - as well as the covariance matrix of all coefficients in the SUR system. Using these and the appropriate factor loadings, the modelimplied response of interest rates can be calculated. In this way, it is possible to calculate the response of interest rates at any maturity, as well as the response of the entire expected future path of short-term interest rates. Importantly, these estimates are based on information from the response of the whole cross section of interest rates to the macroeconomic release, which minimizes the impact of idiosyncratic noise and improves efficiency.

The regression analysis includes data on six different macroeconomic data releases: nonfarm payroll employment, the unemployment rate, hourly earnings, core CPI, and core PPI (all of which come from the BLS) as well as retail sales (released by the Department of Commerce). The sample includes all business days from January 1990 to December 2009.

\footnotetext{
${ }^{22}$ Examples include Kearney and Lombra (2003), Gürkaynak et al. (2005b), and Bartolini et al. (2008).

${ }^{23}$ The only exception, to my knowledge, is a study by Fleming and Remolona (1999), who incorporate macroeconomic announcement data into a term structure model. In contrast, my approach leaves the news outside of the model, which makes the framework simpler and more widely applicable.
} 
I first consider the responses of specific instruments to macro news: Figure 5 shows the estimated impact on Eurodollar futures rates of surprises in each of the six news releases. Model-implied responses, shown as solid lines, correspond well to the empirical responses, which are shown with $95 \%$ confidence intervals, based on White standard errors, as error bars. The good fit is no surprise, since the model accurately fits interest rate changes, thus it naturally also fits responses to macro surprises well. The fit for the responses of yields (not shown) is equally good. Because of the accurate fit, the subsequent analysis focuses on model-implied responses.

Table 1 reports the model-implied responses for several different instruments, namely the ED4 contract, the two-year yield, the ten-year yield, and the nine-to-ten-year forward rate (the last column will be discussed below). Figure 6 shows the revision of short-rate expectations in response to a surprise in each data release, together with $95 \%$ confidence intervals based on White standard errors - this gives the clearest and most intuitive picture of the announcement effects on the term structure of interest rates. The key observations are the following:

- All releases elicit a significant response at some horizons.

- Surprises in the payrolls number have by far the strongest impact on the term structure - forward rates at a two-year horizon respond more than twice as much as to any other surprise.

- The response is always hump-shaped: at the short end it increases (in absolute value), and after reaching a peak at a horizon of about two to three years, it levels out. The increase at the short end indicates that market participants expect the Fed to adjust the target in small steps, indicating monetary policy inertia - this will be discussed further in Section 4.4.

- The responses at distant horizons are generally small and often insignificant.

The issue of the response of long rates deserves closer scrutiny. It is an important question whether the long end of the term structure shows a significant reaction to a macro surprise, or whether the response has a transitory character, because the answer affects what is required of macroeconomic models of monetary policy. This point was made forcefully by Gürkaynak et al. (2005b), who concluded that most releases do affect long rates and that standard macro models are at odds with this finding. The question about the response of the long end of the term structure is not as straightforward as it seems, since the answer depends on what is considered "the long end." If it is the response of the ten-year yield, shown in the third column of Table 1, one might conclude that almost all releases (except for the unemployment 
rate) significantly affect long-term rates. However, since yields are averages of forward rates, a significant response of a long-term yield could be driven by responses of forward rates at shorter horizons. To better isolate the long-term effects, Gürkaynak et al. (2005b) regressed nine-to-ten-year forward rates on macro surprises and concluded that there is sensitivity of long-term rates to most macroeconomic announcements. Table 1 shows in column four the responses of the corresponding model-implied forward rates. Only for three of the six releases, namely for hourly earnings, core CPI, and retail sales, do these forward rates show a statistically significant response, and in those cases the response is generally small in magnitude, only about one basis point.

In contrast to Gürkaynak et al. (2005b), I do not find a significant response of far-ahead forward rates to non-farm payrolls. To clarify this difference, Figure 7 shows the responses of actual and model-implied forward rates to payroll surprises, both with $95 \%$ confidence intervals based on White standard errors. The actual nine-to-ten-year forward rate does show a significant response, but the model-implied rate does not. There seems to be a fair amount of idiosyncratic effects that drive the response of different forward rates. Therefore one is welladvised to incorporate information from the entire term structure, and to smooth through the noise across maturities, in order to get a reliable assessment of the response of nominal rates to macro news. Based on this approach, the puzzling response of far-ahead forward rates to payroll news disappears.

Because the model simultaneously captures the effects on all interest rates, it allows me to directly test the hypothesis for level effects of macroeconomic news. The object of interest is the estimated response of distant forward rates, i.e., of distant (risk-neutral) expectations of short rates, $\lim _{h \rightarrow \infty} E_{t}\left(r_{t+h}\right)$, to macro news. ${ }^{24}$ The last column of the table reports the estimated response coefficient. According to these estimates, only hourly earnings, core CPI, and retail sales significantly affect the long end of the term structure - this parallels the results for the smoothed 9-to-10-year forward rate. Again, there is no response to payroll surprises. Two of the three significant coefficients are only marginally significant (at the 10\% level). Importantly, even the statistically significant coefficients are very small in magnitude, and in this sense do not seem economically important.

Given that the estimated announcement effects for the long end of the term structure are economically and statistically small, macro surprises appear to have only transitory effects on forward rates. This conclusion differs from that of Gürkaynak et al. (2005b), who find significant announcement effects on distant forward rates. The difference in results is due to

\footnotetext{
${ }^{24}$ This forward rate would be zero if $\Phi$ did not have a unit eigenvalue - only if the risk-neutral dynamics have a unit root, as it does here and in Christensen et al. (2011), can infinite-horizon forward rates vary at all.
} 
the fact that I incorporate information from the entire nominal term structure for estimation of announcement effects - this minimizes the impact of idiosyncratic noise, and enables me to directly test for level shifts. Gürkaynak et al. (2005b) conclude that long-run expectations of economic agents should not be viewed as constant, and instead propose models with unanchored inflation expectations due to a time-varying inflation target. My results suggest that the evidence for unanchored long-run expectations is far from conclusive, and that stable long-run expectations are not necessarily at odds with the data.

\subsection{Policy inertia and interest-rate smoothing}

The term "monetary policy inertia" describes the empirical phenomenon that subsequent changes in the policy rate typically go in the same direction. Under rational expectations this will naturally be reflected in the way market participants revise short-rate expectations in response to new information. The evidence above showed the distinct hump shape in response coefficients across maturities and in macro-driven volatility curves. This shape is unlikely to be entirely due to variation in term premia, in particular since these are typically more important for long maturities. It appears that very near-term expectations of policy rates generally move by less than medium-term expectations. Therefore, this evidence supports the view that market participants expect the Fed to display some degree of inertia in its adjustments of the short rate. ${ }^{25}$

The idea that interest rate movements around macroeconomic releases can inform us about expected policy inertia has been formalized by Rudebusch (2006). He proposed to consider changes in forward rates for subsequent quarters around data releases. I present such evidence about such rate changes in Table 2, which, as suggested by Rudebusch, contains means and medians for the ratios of these rate changes. ${ }^{26}$ I consider both actual and model-implied rate changes in the ED3 (ED4) contract relative to the ED2 (ED3) contract, as well as the change in short-rate expectations for horizons of two to four quarters, relative to the change in expectations for the preceding quarter. The table reports medians and means (with standard errors) over all observations that fall on days with the release of either an employment report, CPI/PPI numbers, or retail sales numbers. ${ }^{27}$ All ratios are significantly larger than one, indicating that the interest rate change is typically larger at the longer horizon than at the

\footnotetext{
${ }^{25}$ See also Fleming and Remolona (1999) on the issue of hump-shaped announcement effects, and Piazzesi (2001), who showed how the hump shape of the term structure of volatility (the "back of the snake") can be attributed to policy inertia in the context of a term structure model that incorporates monetary policy.

${ }^{26}$ The fact that I do not use intradaily data is unlikely to change the qualitative results and allows me to use the term structure model to assess the question of interest.

${ }^{27}$ Changes are rounded to whole basis points; observations with zero in the denominator are excluded.
} 
short horizon. In contrast, Rudebusch finds in his yield data sample that the ratio is about unity on average, and concludes "that the case of no or little inertia is the relevant one" (Rudebusch, 2006, p. 29). The results here lead to a different answer, that at the short end of the term structure the response of short-rate expectations to macro news is increasing with horizon. ${ }^{28}$ This evidence clearly supports the case for policy inertia.

While policy inertia can be explained with a desire of the central bank to smooth interest rates and a resulting sluggish adjustment of the policy instrument toward the desired target, Rudebusch $(2002,2006)$ points out that this is not the only possible explanation. If the variables that determine the policy rate - such as the shocks in estimated simple policy rules - are serially correlated, then observed target rate changes will naturally display serial correlation as well. In that case, we would observe policy inertia without an explicit desire on the part of the central bank to smooth movements in the policy rates. The two alternative explanations for policy inertia are hard to empirically distinguish - for a discussion see Rudebusch's papers and, most recently, Coibion and Gorodnichenko (2012) - and on the surface, the evidence above is generally consistent with both explanations of policy inertia. However, Rudebusch (2006, Section 3.3) has demonstrated that under plausible assumptions, the relative magnitude of responses to macro announcements for forward rates covering subsequent quarters can provide evidence about the degree of interest-rate smoothing. Under these assumptions, the ratio of subsequent quarterly changes is on average equal to $\delta+\rho$, with $\delta$ being the autoregressive coefficient of the inflation process, which we can safely take to be equal to one, and $\rho$ being the interest-rate smoothing parameter of the policy rule. Since Rudebusch finds this ratio to be insignificantly different from one, he concludes that there is no convincing evidence for interest-rate smoothing. However, the evidence in Table 2 suggests the opposite conclusion. The table shows alternative estimates of $1+\rho$, based on different ratios of interest rate changes. Evidently, values for $\rho$ of 0.2 to 0.5 are consistent with the data. These estimates are sizable and statistically significant. This evidence is consistent with the view that the Fed puts considerable weight, up to $50 \%$, on last quarter's short rate when it adjusts the policy rate.

In sum, estimates of interest rate movements around macroeconomic announcements, obtained by incorporating the information from the entire term structure using the arbitrage-free model, provide evidence of both policy inertia and interest-rate smoothing. In response to new macroeconomic data, market participants revise their expectations in a way which shows that they expect inertial adjustments of the policy rate by the Federal Reserve toward the

\footnotetext{
${ }^{28}$ Additional results (not shown) suggest that this finding is robust to the use of alternative data samples and instruments.
} 
desired level.

\section{$5 \quad$ Policy news vs. macro news}

Because the econometric model captures the different sources of news within one framework, I can assess the question whether there are systematic differences in how these affect interest rates. The parsimonious representation of interest rates is particularly advantageous in this context. In the absence of a yield curve model, a comparison would have to be made using observed interest rates, requiring the consideration of a large set of instruments to obtain a complete picture. In contrast, the model fully captures the volatility and comovement of all interest rates in regime $l$ with the $3 \times 3$ matrix $\Omega_{l}$. To compare how different types of news affect the term structure, we can thus simply compare these covariance matrices.

\subsection{The level of volatility}

In Section 3 we saw that policy surprises appear to cause a similar amount of volatility as macroeconomic news (see Figure 3). To investigate this more formally, I test whether the volatilities are significantly different across regimes, using a Bartlett test for homogeneity of variances (Bartlett, 1937). Due to the parsimony of the model, this test needs to be carried out only three times, for each of the three risk factors, instead of having to test the null of equal variance for each Eurodollar futures contract and Treasury yield maturity separately.

First, I compare the variances of the risk factors due to policy news (regime 1) to those due to macroeconomic news (regimes 2 to 4 ). The $p$-values of the level, slope, and curvature factors are $0.979,9.466$, and 0.255 , respectively. Based on this test, there is no evidence that policy news causes a different amount of volatility in interest rates than macroeconomic news. Notably, this test pools the different types of macroeconomic news and compares the variance on all macro announcement days to that on policy days. But macroeconomic news display substantial heterogeneity, evident from Figure 3 and confirmed by a Bartlett test for equal variances across regimes 2 to 4 , which strongly rejects equal variances (all $p$-values are below 0.001). In light of this heterogeneity, it is an obvious question to ask which type of macroeconomic news, if any, policy news appear similar to. To this end, I test for equal variances for each policy-macro regime pair. Equality of variance is rejected in the case of employment news ( $p$-values are 0.001/0.170/0.000) and CPI news (0.001, 0.001, 0.069),

but that there is no significant difference in variances between policy news and retail sales $(0.327 / 0.722 / 0.772)$. Overall, we can conclude that policy news cause a similar amount of 
volatility as macroeconomic news.

The Bartlett test can also be used to investigate more formally whether policy days generate significant volatility relative to other days. For this purpose, regime 5 is taken as representing days with no major news. ${ }^{29}$ The null of equal variance between regimes 1 and 5 is rejected for all three risk factors with $p$-values below 0.001. This evidence substantiates the claim that monetary policy actions are a major source of interest rate volatility.

\subsection{The comovement of interest rates}

Regarding the comovement of interest rates, Section 3 already documented that monetary policy news cannot be captured by just one number (see also Gürkaynak et al., 2005a). Intuitively, monetary policy surprises appear to have more than one dimension. How can we formalize this? Is this also true for macroeconomic surprises? How many common components drive changes in interest rates in each case?

Table 3 shows statistics that describe comovement of interest rates in each of the five sub-samples. First, it reports the correlation between revisions of short-rate expectations at horizons of three months and five years, and pairwise correlations of the three risk factors. On days with macroeconomic news, the correlations are generally much stronger than on days with policy actions. For the correlation between changes in the level and slope factor, days with macro news show a comovement that is about twice as strong as on policy days. An eigenvalue decomposition reveals how many factors are necessary to explain interest rate movements in response to specific types of news. The table shows the energy component (the ratio of the eigenvalue to the sum of eigenvalues) for each of the three principal components (PCs), reflecting how much each PC contributes to total variability. On days with policy news the first PC contributes $85.1 \%$ to the variance and the second PC $12 \%$. On the other hand in the macro news regimes the contribution of the first PC is much higher, 92-95\%, and the second $\mathrm{PC}$ contributes a maximum of about 5\%. The second $\mathrm{PC}$ is more than twice as important for policy news than for days with macro news. To test whether one factor is sufficient to capture interest rate movements, against the alternative hypothesis that two factors or more are needed, I use a test developed by Onatski (2009). The table reports pvalues for both the static and dynamic version of Onatski's test. ${ }^{30}$ Both tests reject the null of one factor on days with policy news, but do not reject this null for days with macroeconomic announcements.

\footnotetext{
${ }^{29}$ As mentioned above, constructing a regime which also excludes days with several other major macroeconomic announcements does not affect the results

${ }^{30}$ Onatski's MATLAB code is available at http://www. columbia.edu/ ao2027/ (accessed 11/30/2011).
} 
In sum, while one factor seems to drive almost all of the variation in the risk factors due to macro news, a second factor is needed in the case of monetary policy surprises. ${ }^{31}$ Evidently, the comovement of interest rate changes across maturities is much stronger when the news comes from macroeconomic announcements. This apparent difference in comovement is statistically significant: Box's $M$-test (Box, 1949) for testing homogeneity of covariances gives a $p$-value that is less than 0.0001, providing strong evidence that the comovement of interest rates is different between days with policy news and those with macro news.

What is the economics behind these findings? Yield curve shifts in each macro news regime usually come in very similar shapes, while on days with policy actions they tend to have more varied shapes. Monetary policy surprises markets along more than one dimension - the FOMC statement contains not only a target rate decision but additional pieces of information that can independently move medium- and longer-term interest rates. This makes the impact of monetary policy on the term structure more complex. Two examples of how the Fed can surprise bond markets were given in Figure 1, notably with similar rate changes at short maturities but completely opposite movements at the long end. In other words, for monetary policy actions there can be different pieces of news for different parts of the term structure. On the other hand macroeconomic data releases typically have one major piece of new information and therefore surprise markets in a one-dimensional fashion. The entire term structure is affected by the magnitude of the surprise related to this one number. For these reasons, monetary policy news is multidimensional, but macroeconomic news is one-dimensional.

\section{Conclusion}

This paper introduces a new framework to estimate and understand the effects of monetary policy surprises and macroeconomic announcements on nominal interest rates. A simple noarbitrage model is used to parsimoniously capture the impact of news on the entire term structure. In this way, the analysis goes beyond the usual instrument-by-instrument regressions that are common in this literature. The model provides for an integrated analysis of different types of news by allowing for heterogeneous sources of volatility, which allows me to separately characterize and compare the different sources of news.

Throughout the paper, the cross-sectional movements of interest rates are the focus of the analysis, and no distinction is attempted between real-world expectations of future short rates

\footnotetext{
${ }^{31}$ While at most two factors (i.e., linear combinations of interest rates) are needed to explain movements in response to specific news, term structure models generally need three factors to fit yields well. They need to capture every imaginable movement in the term structure, for all possible sources of news, and therefore require more flexibility than when the focus is on one specific source of news.
} 
and term premia. Expectations are unobserved, and the high persistence of interest rates makes it very difficult to accurately estimate a time-series model to infer them in the context of a DTSM. Possible remedies include the use of survey-information (Kim and Orphanides, 2012), direct correction of small-sample bias Bauer et al. (2012), and restrictions on risk prices Bauer (2011a). Using these tools to assess how policy and macro news affect real-world expectations and term premia is a fruitful avenue for future research. An important related question is to which extent the interest-rate responses to news are due to real-rate movements and inflation expectations. This question is partly addressed in Gürkaynak et al. (2010), Beechey et al. (2011), Nakamura and Steinsson (2013), and Bauer (2011b), but these studies neither incorporate the various rates and inflation measures across maturities in a coherent term structure model nor satisfactorily account for movements in inflation risk premia. Much work about the effects of policy and macro news on the term structure of interest rates remains to be done.

The methodology presented in this paper could be applied to better understand the response of stock markets to policy and macro news. Since the model captures the response of nominal rates, it could be used to decompose the response of stock markets into one component due to cash flow news and a second component due to discount rate news, along the lines of Bernanke and Kuttner (2005). Another natural application of the model would be to assess the evidence on central bank transparency, accounting for the heterogeneity of policy news over different historical episodes (e.g., pre/post 1994). Furthermore, the model could be used to separately analyze the effects of monetary policy actions at a finer level of granularity, differentiating policy actions along dimensions such as tightening vs. easing, magnitude of the surprise, the importance of forward guidance, and conventional vs. unconventional monetary policy.

\section{References}

Ang, Andrew and Monika Piazzesi, "A no-arbitrage vector autoregression of term structure dynamics with macroeconomic and latent variables," Journal of Monetary Economics, May 2003, 50 (4), 745-787.

Balduzzi, Pierluigi, E. J. Elton, and T. C. Green, "Economic News and Bond Prices: Evidence from the U.S. Treasury Market," Journal of Financial and Quantitative Analysis, December 2001, 36 (4), 523-544. 
Bansal, Ravi and Hao Zhou, "Term Structure of Interest Rates with Regime Shifts," Journal of Finance, October 2002, 57 (5), 1997-2043.

Bartlett, Maurice S., "Properties of sufficiency and statistical tests," Proceedings of the Royal Society of London. Series A-Mathematical and Physical Sciences, 1937, 160 (901), 268-282.

Bartolini, Leonardo, Linda S. Goldberg, and Adam Sacarny, "How Economic News Moves Markets," Current Issues in Economics and Finance, August 2008, 14 (6).

Bauer, Michael D., "Bayesian Estimation of Dynamic Term Structure Models under Restrictions on Risk Pricing," Working Paper 2011-03, Federal Reserve Bank of San Francisco November 2011.

_ , "Inflation Expectations and the News," unpublished manuscript 2011.

- and Glenn D. Rudebusch, "The Signaling Channel for Federal Reserve Bond Purchases," Working paper 2011-21, Federal Reserve Bank of San Francisco April 2013.

_ , _, and Jing Cynthia Wu, "Correcting Estimation Bias in Dynamic Term Structure Models," Journal of Business and Economic Statistics, July 2012, 30 (3), 454-467.

Beechey, Meredith J., Benjamin K. Johannsen, , and Andrew T. Levin, "Are LongRun Inflation Expectations Anchored More Firmly in the Euro Area than in the United States?," American Economic Journal: Macroeconomics, 2011, 3 (2), 104-129.

Bernanke, Ben S. and Kenneth N. Kuttner, "What Explains the Stock Market's Reaction to Federal Reserve Policy?," Journal of Finance, 06 2005, 60 (3), 1221-1257.

Box, George E.P., "A general distribution theory for a class of likelihood criteria," Biometrika, 1949, 36 (3/4), 317-346.

Christensen, Jens H. E., Francis X. Diebold, and Glenn D. Rudebusch, "The Affine Arbitrage-Free Class of Nelson-Siegel Term Structure Models," Journal of Econometrics, September 2011, 164 (1), 4-20.

Coibion, Olivier and Yuiy Gorodnichenko, "Why Are Target Interest Rate Changes So Persistent?," American Economic Journal: Macroeconomics, 2012, 4 (4), 126-162.

Dai, Qiang and Kenneth J. Singleton, "Term Structure Dynamics in Theory and Reality," Review of Financial Studies, 2003, 16 (3), 631-678. 
Duffie, Darrell and Rui Kan, "A Yield-Factor Model of Interest Rates," Mathematical Finance, 1996, 6 (4), 379-406.

Faust, Jon, John H. Rogers, Shing-Yi B. Wang, and Jonathan H. Wright, "The highfrequency response of exchange rates and interest rates to macroeconomic announcements," Journal of Monetary Economics, May 2007, 54 (4), 1051-1068.

Fleming, Michael J. and Eli M. Remolona, "What moves the bond market?," Economic Policy Review, December 1997, pp. 31-50.

_ and _ , "The term structure of announcement effects," BIS Working Papers 71, Bank for International Settlements June 1999.

Gagnon, Joseph, Matthew Raskin, Julie Remache, and Brian Sack, "The Financial Market Effects of the Federal Reserve's Large-Scale Asset Purchases," International Journal of Central Banking, March 2011, 7 (1), 3-43.

Gürkaynak, Refet S., Andrew T. Levin, and Eric T. Swanson, "Does Inflation Targeting Anchor Long-Run Inflation Expectations? Evidence from the U.S., U.K., and Sweden," Journal of the European Economic Association, December 2010, 8 (6), 1208-1242.

_, Brian P. Sack, and Eric T. Swanson, "Do Actions Speak Louder Than Words? The Response of Asset Prices to Monetary Policy Actions and Statements," International Journal of Central Banking, May 2005, 1 (1), 55-93.

_ , _ , and _ , "The Sensitivity of Long-Term Interest Rates to Economic News: Evidence and Implications for Macroeconomic Models," American Economic Review, March 2005, 95 (1), 425-436.

Hamilton, James D., "Assessing monetary policy effects using daily federal funds futures contracts," Federal Reserve Bank of St. Louis Review, Jul 2008, pp. 377-394.

_ , "Daily Changes in Fed Funds Futures Prices," Journal of Money, Credit and Banking, 06 2009, $41(4), 567-582$.

Jegadeesh, Narasimhan and George G. Pennacchi, "The Behavior of Interest Rates Implied by the Term Structure of Eurodollar Futures," Journal of Money, Credit and Banking, August 1996, 28 (3), 426-46.

Jones, Charles M., Owen Lamont, and Robin L. Lumsdaine, "Macroeconomic news and bond market volatility," Journal of Financial Economics, 1998, 47 (3), 315-337. 
Joslin, Scott, Kenneth J. Singleton, and Haoxiang Zhu, "A New Perspective on Gaussian Dynamic Term Structure Models," Review of Financial Studies, March 2011, 24 (3), 926-970.

Kearney, Adrienne and Raymond Lombra, "Fed funds futures and the news," Atlantic Economic Journal, December 2003, 31 (4), 330-337.

Kim, Don H. and Athanasios Orphanides, "Term Structure Estimation with Survey Data on Interest Rate Forecasts," Journal of Financial and Quantitative Analysis, February 2012, $47(1), 241-272$.

Kohn, Donald L. and Brian P. Sack, "Central bank talk: does it matter and why?," in "Macroeconomics, monetary policy, and financial stability: a festschrift in honour of Charles Freedman" Bank of Canada 2004, pp. 175-2006. Proceedings of a conference held by the Bank of Canada in June 2003.

Kuttner, Kenneth N., "Monetary Policy Surprises and Interest Rates: Evidence from the Fed Funds Futures Market," Journal of Monetary Economics, June 2001, 47 (3), 523-544.

Litterman, Robert and J. Scheinkman, "Common Factors Affecting Bond Returns," Journal of Fixed Income, June 1991, 1 (1), 54-61.

Monfort, Alain and Fulvio Pegoraro, "Switching VARMA Term Structure Models," Journal of Financial Econometrics, 2007, 5 (1), 105-153.

Nakamura, Emi and Jon Steinsson, "High Frequency Identification of Monetary NonNeutrality," Working Paper 19260, Fnational Bureau of Economic Research July 2013.

Onatski, Alexei, "Testing hypotheses about the number of factors in large factor models," Econometrica, September 2009, 77 (5), 1447-1479.

Piazzesi, Monika, "An Econometric Model of the Yield Curve with Macroeconomic Jump Effects," NBER Working Papers 8246, National Bureau of Economic Research April 2001.

- and Eric T. Swanson, "Futures prices as risk-adjusted forecasts of monetary policy," Journal of Monetary Economics, May 2008, 55 (4), 677-691.

Poole, William and Robert H. Rasche, "Perfecting the Market's Knowledge of Monetary Policy," Journal of Financial Services Research, 2000, 18 (2/3), 255-298. 
Rigobon, Roberto and Brian P. Sack, "The impact of monetary policy on asset prices," Journal of Monetary Economics, November 2004, 51 (8), 1553-1575.

_ and _ , "Noisy Macroeconomic Announcements, Monetary Policy, and Asset Prices," in John Y. Campbell, ed., Asset Prices and Monetary Policy, University of Chicago Press September 2008, pp. 335-370.

Rudebusch, Glenn D., "Term structure evidence on interest rate smoothing and monetary policy inertia," Journal of Monetary Economics, 2002, 49 (6), 1161-1187.

_ , "Monetary Policy Inertia: Fact or Fiction?," International Journal of Central Banking, December 2006, 2 (4), 85-135.

Singleton, Kenneth J., Empirical Dynamic Asset Pricing, Princeton University Press, 2006.

Zellner, Arnold, "An Efficient Method of Estimating Seemingly Unrelated Regressions and Tests for Aggregation Bias," Journal of the American Statistical Association, June 1962, 57 (298), 348-368. 


\section{A Affine loadings for yields and forward rates}

The price of an $n$-period zero coupon bond at time $t$ is given by

$$
P_{t}^{n}=\exp \left(\mathcal{A}_{n}+\mathcal{B}_{n} \mathcal{P}_{t}\right)
$$

where the bond price loadings $\mathcal{A}_{n}$ and $\mathcal{B}_{n}$ are determined by

$$
\begin{aligned}
\mathcal{A}_{n+1} & =\mathcal{A}_{n}+\mu^{\prime} \mathcal{B}_{n}+\frac{1}{2} \mathcal{B}_{n}^{\prime} \Omega \mathcal{B}_{n}-\delta_{0} \\
\mathcal{B}_{n+1} & =\Phi^{\prime} \mathcal{B}_{n}-\delta_{1}
\end{aligned}
$$

and the initial conditions $\mathcal{A}_{0}=0, \mathcal{B}_{0}=0$. The yield loadings are given by $A_{n}=-\mathcal{A}_{n} / n$ and $B_{n}=-\mathcal{B}_{n} / n$. The derivation can be found, for example, in Dai and Singleton (2003).

For a forward rate for a loan from $t+n$ to $t+n+1$ we have $f_{t}^{n}=\log \left(P_{t}^{n}\right)-\log \left(P_{t}^{n+1}\right)=$ $\mathcal{A}_{n}-\mathcal{A}_{n+1}+\left(\mathcal{B}_{n}-\mathcal{B}_{n+1}\right)^{\prime} \mathcal{P}_{t}$ so that the forward rate loadings are given by

$$
\begin{aligned}
A_{n}^{f} & =-\mu^{\prime} \mathcal{B}_{n}-\frac{1}{2} \mathcal{B}_{n}^{\prime} \Omega \mathcal{B}_{n}+\delta_{0} \\
B_{n}^{f} & =\Phi^{n \prime} \delta_{1} .
\end{aligned}
$$

To see that $B_{n}^{f}=\left(\mathcal{B}_{n}-\mathcal{B}_{n+1}\right)=(\Phi)^{n^{\prime}} \delta_{1}$ note that $\mathcal{B}_{n}=-\left[I_{N}+\Phi+\ldots+\Phi^{n-1}\right]^{\prime} \delta_{1}$.

\section{B Revisions to short-rate expectations}

For the risk-neutral expectations of future $\mathcal{P}_{t}$ the $\operatorname{VAR}(1)$ specification implies

$$
E_{t} \mathcal{P}_{t+n}=\left[I_{N}+\Phi+\ldots+\Phi^{n-1}\right] \mu+\Phi \mathcal{P}_{t}
$$

Therefore, we have for the change in the risk-neutral expectation, between days $t-1$ and $t$, of the future short rate at $r_{t+n}$

$$
\begin{aligned}
R_{t}^{n} & =\left(E_{t}-E_{t-1}\right) r_{t+n} \\
& =\delta_{1}^{\prime}\left(E_{t} \mathcal{P}_{t+n}-E_{t-1} \mathcal{P}_{t+n}\right) \\
& =\delta_{1}^{\prime}\left[-\Phi^{n} \mu+\Phi^{n}\left(\mu+\Phi \mathcal{P}_{t-1}+u_{t}\right)+\Phi^{n+1} \mathcal{P}_{t+1}\right] \\
& =\delta_{1}^{\prime} \Phi^{n} u_{t}=B_{n}^{f^{\prime}} u_{t} .
\end{aligned}
$$


The drift in forward rates is

$$
\begin{aligned}
f_{t}^{n}-f_{t-1}^{n+1} & =A_{n}^{f}-A_{n+1}^{f}+B_{n}^{f^{\prime}} \mathcal{P}_{t}-B_{n+1}^{f}{ }^{\prime} \mathcal{P}_{t-1} \\
& =-\mu^{\prime} \mathcal{B}_{n}+\mu^{\prime} \mathcal{B}_{n+1}+B_{n}^{f^{\prime}} \mathcal{P}_{t}-B_{n+1}^{f}{ }^{\prime} \mathcal{P}_{t-1}+\Delta c o n v \\
& =-\mu^{\prime} B_{n}^{f}+B_{n}^{f^{\prime}}\left(\mu+\Phi \mathcal{P}_{t-1}+u_{t}\right)-B_{n}^{f^{\prime}} \Phi \mathcal{P}_{t-1}+\Delta c o n v \\
& =B_{n}^{f^{\prime}} u_{t}+\Delta \text { conv }=R_{t}^{n}+\Delta \text { conv },
\end{aligned}
$$

where $\Delta$ conv $=\frac{1}{2} \mathcal{B}_{n}^{\prime} \Omega \mathcal{B}_{n}-\frac{1}{2} \mathcal{B}_{n+1}^{\prime} \Omega \mathcal{B}_{n+1}$ stands for the change in convexity that comes with the shortening of the maturity. For daily changes this term is negligibly small.

\section{Pricing of money market futures}

Federal funds futures settle based on the average effective federal funds rate over the course of the contract month. Denote the futures rate at time $t$ of the $i$-month-ahead contract by $F F_{t}^{(i)}$, and the contract itself by FFi. Letting $m(t)$ be the day of the month corresponding to calendar day $t$, and $M$ the number of days in a month (taken as 21, the average number of business days per month), settlement is based on the average short rate from $t+i M-m(t)+1$ to $t+(i+1) M-m(t)$. Since the cost to enter the contract is zero and the payoff ${ }^{32}$ is proportional to the difference between the futures rate and the settlement rate, the pricing equation is

$$
0=E_{t}\left(F F_{t}^{(i)}-M^{-1} \sum_{n=i M-m(t)+1}^{(i+1) M-m(t)} r_{t+n}\right)
$$

The futures rate is exactly equal to the average expected short rate under the risk-neutral probability measure. There are no convexity terms as for forward rates because the payoff is linear in the average future short rate.

Eurodollar futures settle based on the three-month LIBOR rate on the settlement day, which is the last day of the relevant quarter. ${ }^{33}$ In this paper I abstract from the credit risk that is inherent in three-month loans in the interbank market. ${ }^{34}$ Denote the rate for the

\footnotetext{
${ }^{32}$ Here the effect of marking-to-market, i.e. the fact that payments are made before settlement, is ignored. Evidence of Piazzesi and Swanson (2008) indicates that this effect is likely to be negligible in this context.

${ }^{33}$ For detailed information on Eurodollar futures contracts refer to the Chicago Mercantile Exchange's web site at http://www.cmegroup.com/trading/interest-rates/stir/eurodollar.html (accessed 08/23/2010).

${ }^{34}$ The credit risk resulting from commitment to a specific counter-party for three months instead of rolling over daily loans at the fed funds rate is measured by the LIBOR-OIS spread. Before August 2007 this spread was small and very stable. During the financial crisis, it increased dramatically since the interbank market essentially froze up. However, under the assumption that changes in the (forward-looking) futures rates mainly reflect changes in risk-neutral short-rate expectations and not changes in expected LIBOR-OIS spread, it is
} 
Eurodollar futures contract that settles at the end of quarter $i$, where $i=1$ corresponds to the current quarter, by $E D_{t}^{(i)}$, and the contract itself by EDi. The pricing equation for this rate parallels the one for Fed funds futures:

$$
0=E_{t}\left(E D_{t}^{(i)}-Q^{-1} \sum_{n=i Q-q(t)+1}^{(i+1) Q-q(t)} r_{t+n}\right)
$$

with $Q$ equal to the number of days in a quarter (taken to be 63, the average number of business days in a quarter) and $q(t)$ the day of the quarter for calendar day $t .{ }^{35}$

For two consecutive days in the same calendar month, the daily change in a fed funds futures rate is $F F_{t}^{(i)}-F F_{t-1}^{(i)}=M^{-1} \sum_{n=i M-m(t)+1}^{(i+1) M-m(t)} R_{t}^{n}$. Correspondingly, for two consecutive days in the same quarter the daily change in a Eurodollar futures rate is $E D_{t}^{(i)}-E D_{t-1}^{(i)}=$ $Q^{-1} \sum_{n=i Q-q(t)+1}^{(i+1) Q-q(t)} R_{t}^{n}$. That is, changes in futures rates exactly reflect the average revision over the relevant future horizon. There are no convexity terms because payoffs are linear in future short rates. There are no drift terms because the rate at $t-1$ and at $t$ are about the exact same future horizon.

Under the assumptions of the model, equations (6) and (7) lead to expressions for futures rates that are affine functions of $\mathcal{P}_{t}$. Similarly, daily changes are affine functions of the riskneutral innovations $u_{t}$. However, the loadings differ depending on $m(t)$ and $q(t)$, respectively, because the relevant horizon of future short-rate expectations changes with the day of the month/quarter. It greatly simplifies the calculations and eases the computational burden to take $m(t)$ and $q(t)$ as constant and thus obtain time-invariant loadings. I set $m(t)=\bar{m}=10$ and $q(t)=\bar{q}=31$, pretending we are always in the middle of the month/quarter. For our purpose this is an innocuous approximation. It leads to the affine functions

$$
\begin{aligned}
& F F_{t}^{(i)}=A_{F F i}+B_{F F i}^{\prime} \mathcal{P}_{t}, \quad \Delta F F_{t}^{(i)}=B_{F F i}^{\prime} \Delta \mathcal{P}_{t} \\
& E D_{t}^{(i)}=A_{E D i}+B_{E D i}^{\prime} \mathcal{P}_{t}, \quad \Delta E D_{t}^{(i)}=B_{E D i}^{\prime} \Delta \mathcal{P}_{t} .
\end{aligned}
$$

with the affine loadings derived in the following.

Denote by $\hat{f}_{t}^{n}$ a hypothetical futures rate for a contract that pays off proportional to the short rate at $t+n$. It corresponds to $f_{t}^{n}$ but does not have any convexity. We have

safe to ignore this issue. This assumption seems plausible for most days, with the exception of a few very turbulent days during the crisis.

${ }^{35}$ The pricing formula derived here differs from Jegadeesh and Pennacchi (1996) because these authors treat LIBOR as the yield on a hypothetical three-month bond. In light of the fact that the LIBOR rate is set based on a survey of intrabank rates, which are via no-arbitrage directly determined by risk-adjusted monetary policy expectations, the approach here seems preferable. 
$\hat{f}_{t}^{n}=E_{t} r_{t+n}=\hat{A}_{n}^{f}+\hat{B}_{n}^{f^{\prime}} \mathcal{P}_{t}$ with loadings given by

$$
\begin{aligned}
& \hat{A}_{n}^{f}=\delta_{0}-\mu^{\prime} \mathcal{B}_{n}=\delta_{0}+\delta_{1}^{\prime}\left[I_{N}+\Phi+\ldots+\Phi^{n-1}\right] \mu \\
& \hat{B}_{n}^{f}=\Phi^{n \prime} \delta_{1} .
\end{aligned}
$$

Note that $\hat{f}_{t}^{n}-\hat{f}_{t-1}^{n+1}=R_{t}^{n}$.

The rates of money market futures are averages of $\hat{f}_{t}^{n}$ over the horizon relevant to the futures contract. Specifically,

$$
\begin{aligned}
& F F_{t}^{(i)}=M^{-1} \sum_{n=i M-\bar{m}+1}^{(i+1) M-\bar{m}} \hat{f}_{t}^{n}, \\
& E D_{t}^{(i)}=Q^{-1} \sum_{n=i Q-\bar{q}+1}^{(i+1) Q-\bar{q}} \hat{f}_{t}^{n},
\end{aligned}
$$

so that we have for the affine loadings of the futures rates

$$
\begin{array}{ll}
A_{F F i}=M^{-1} \sum_{n=i M-\bar{m}+1}^{(i+1) M-\bar{m}} \hat{A}_{n}^{f}, & B_{F F i}=M^{-1} \sum_{n=i M-\bar{m}+1}^{(i+1) M-\bar{B}} \hat{B}_{n}^{f} \\
A_{E D i}=Q^{-1} \sum_{n=i Q-\bar{q}+1}^{(i+1) Q-\bar{q}} \hat{A}_{n}^{f}, & B_{E D i}=Q^{-1} \sum_{n=i Q-\bar{q}+1}^{(i+1) Q-\bar{q}} \hat{B}_{n}^{f} .
\end{array}
$$

\section{Intraday volatilities around policy actions}

My measure of the policy surprise, the revision on a day with a policy action, contains noise since there is other news on day $t$ that also affects rates. Going to intraday data increases the precision, but it precludes the use of a term structure model. Here I show additional (modelfree) results based on intradaily changes around FOMC announcements and demonstrate the robustness of my results.

I perform a similar analysis using the intraday yield changes around FOMC announcements that were used by Gürkaynak et al. (2005a). ${ }^{36}$ The data set contains yields with maturities three months, six months, and two, five, and ten years, and spans the policy actions from July 1991 to December 2004. I calculate volatilities for tight-window changes (30 minutes), wide-window changes (60 minutes), and daily changes.

\footnotetext{
${ }^{36}$ I thank Eric Swanson for providing me with these data.
} 
Policy days

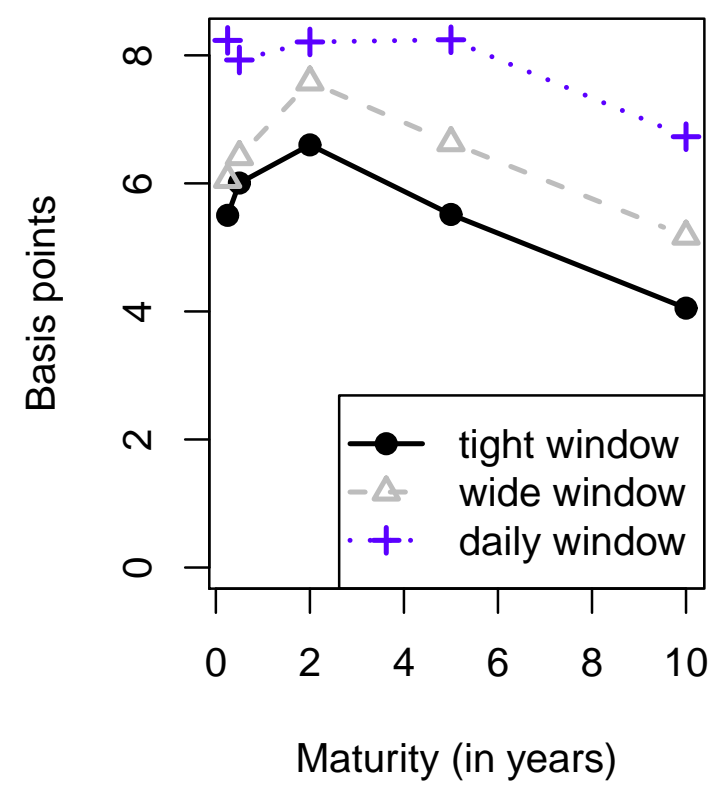

All days

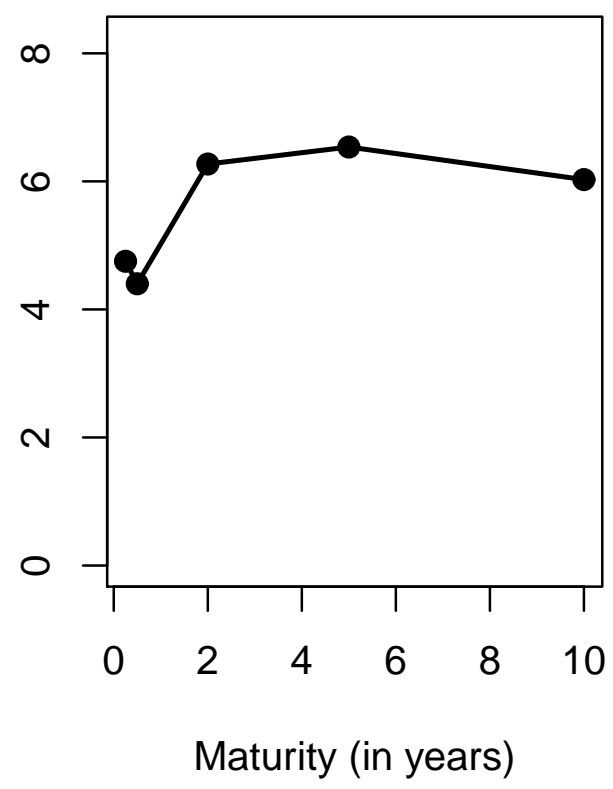

Notes: Left panel shows sample standard deviations for changes in Treasury yields around policy actions, from July 1991 to December 2004, using a tight (30 minute) window, a wide (60 minute) window, and a daily window. Right panel shows unconditional volatilities, using all days in the sample, for the same maturities and sample period.

The figure shows the resulting intradaily volatilities around policy events in the left panel and the unconditional daily volatilities for the same maturities and sample period in the right panel. Intradaily volatilities around policy actions are lower than those calculated using daily changes, which is natural since the news during the remainder of the day are left out. Comparing the policy-induced volatilities at the short and at the long end, they are slightly smaller at the long end in this sample. However, this holds for both daily and intradaily changes: estimating volatilities using a tight window around policy announcements does not change the relative magnitude of volatilities at the long end vs. at the short end. 
Table 1: Effects of macroeconomic announcements

\begin{tabular}{l|cccc|c}
\hline \hline News release & ED4 & $2 \mathrm{y}$ yield & 10y yield & 9 -to-10 fwd & $\lim _{h \rightarrow \infty} E_{t}\left(r_{t+h}\right)$ \\
\hline Payrolls & $6.89^{* * *}$ & $5.92^{* * *}$ & $2.77^{* * *}$ & -0.02 & -0.24 \\
\multirow{4}{*}{ Unemployment rate } & $(0.82)$ & $(0.69)$ & $(0.57)$ & $(0.53)$ & $(0.53)$ \\
& $-1.64^{* *}$ & $-1.51^{* * *}$ & -0.50 & 0.17 & 0.21 \\
Hourly earnings & $(0.65)$ & $(0.56)$ & $(0.51)$ & $(0.56)$ & $(0.56)$ \\
& $2.24^{* * *}$ & $2.00^{* * *}$ & $1.57^{* * *}$ & $1.06^{*}$ & $1.01^{*}$ \\
Core CPI & $(0.70)$ & $(0.59)$ & $(0.57)$ & $(0.59)$ & $(0.59)$ \\
& $2.78^{* * *}$ & $2.45^{* * *}$ & $2.06^{* * *}$ & $1.44^{*}$ & $1.38^{*}$ \\
Core PPI & $(0.60)$ & $(0.52)$ & $(0.63)$ & $(0.74)$ & $(0.75)$ \\
\multirow{3}{*}{ Retail sales } & 0.72 & $0.62^{*}$ & $0.77^{* *}$ & 0.72 & 0.71 \\
& $(0.44)$ & $(0.37)$ & $(0.38)$ & $(0.45)$ & $(0.46)$ \\
& $2.41^{* * *}$ & $2.11^{* * *}$ & $1.63^{* * *}$ & $1.01^{* *}$ & $0.95^{* *}$ \\
& $(0.45)$ & $(0.39)$ & $(0.38)$ & $(0.45)$ & $(0.46)$ \\
\hline
\end{tabular}

Notes: Responses of model-implied interest rates to a one-standard-deviation surprise in six different macroeconomic data releases. ED4 denotes the three-quarters-ahead Eurodollar futures contract. $\lim _{h \rightarrow \infty} E_{t}\left(r_{t+h}\right)$ denotes distant-horizon (risk-adjusted) short-rate expectations, i.e., the long end of the term structure. The estimation sample contains all days with at least one macroeconomic announcement but without policy action, from January 1990 to December 2009. Numbers in parentheses are White standard errors. *, **, and *** denote significance at 10\%, $5 \%$, and $1 \%$ level, respectively. 
Table 2: Policy inertia: ratios of near-term rate changes on announcement days

\begin{tabular}{llccccc}
\hline \hline & & $\Delta E D_{t}^{(3)}$ & $\Delta E D_{t}^{(4)}$ & $\frac{\Delta E_{t}\left(r_{t+6 m}\right)}{\Delta E_{t}\left(r_{t+3 m}\right)}$ & $\frac{\Delta E_{t}\left(r_{t+9 m}\right)}{\Delta E_{t}\left(r_{t+6 m}\right)}$ & $\frac{\Delta E_{t}\left(r_{t+12 m}\right)}{\Delta E_{t}\left(r_{t+9 m}\right)}$ \\
\cline { 3 - 6 } Fitted & median & 1.25 & 1.12 & 1.40 & 1.25 & 1.12 \\
& mean & 1.27 & 1.16 & 1.48 & 1.28 & 1.16 \\
& (s.e.) & $(0.02)$ & $(0.01)$ & $(0.05)$ & $(0.02)$ & 0.01 \\
\hline Actual & median & 1.29 & 1.10 & & & \\
& mean & 1.38 & 1.16 & & & \\
& (s.e.) & $(0.03)$ & $(0.02)$ & & & \\
\hline \hline
\end{tabular}

Notes: Medians, means, and standard errors for the mean for relative changes in actual and model-implied rates. $E D_{t}^{(i)}$ denotes the rate of the $(i-1)$-quarters-ahead Eurodollar futures contract. The sample contains all days with release of either an employment report, CPI/PPI numbers, or retail sales numbers, from January 1990 to December 2009 (663 observations). Rate changes are rounded to basis points, observations with zero change in the denominator are excluded.

Table 3: Policy vs. macro news: factor comovements

\begin{tabular}{l|cccc|ccc|cc}
\hline \hline & \multicolumn{4}{|c|}{ Correlations } & \multicolumn{3}{|c|}{ Energy content (\%) } & \multicolumn{2}{c}{ Onatski's test } \\
News regime & $(3 \mathrm{~m}, 5 \mathrm{y})$ & $(\mathrm{l}, \mathrm{s})$ & $(\mathrm{l}, \mathrm{c})$ & $(\mathrm{s}, \mathrm{c})$ & $P C_{1}$ & $P C_{2}$ & $P C_{3}$ & static & dynamic \\
\hline FOMC & 0.34 & -0.40 & -0.49 & 0.47 & 85.1 & 12.2 & 2.9 & 0.010 & 0.021 \\
Employment & 0.55 & -0.81 & -0.84 & 0.63 & 94.9 & 3.7 & 1.4 & 0.194 & 0.331 \\
CPI/PPI & 0.54 & -0.82 & -0.66 & 0.43 & 92.7 & 4.9 & 2.4 & 0.898 & 0.938 \\
Retail & 0.43 & -0.84 & -0.75 & 0.50 & 93.3 & 5.1 & 1.5 & 0.506 & 0.489 \\
Other days & 0.48 & -0.75 & -0.58 & 0.41 & 90.7 & 6.1 & 3.2 & 0.666 & 0.040
\end{tabular}

Notes: For each sub-sample, the table shows statistics for the comovement of interest rate changes at different horizons. The first column shows the correlation between the changes in short-rate expectations at horizons of three months and five years. Columns two to four show pairwise correlations between changes in the risk factors (level, slope, and curvature). Columns five to seven show the energy content, i.e., the eigenvalue divided by the sum of the eigenvalues, of each principal component (PC) of changes in the risk factors. The last two columns show p-values from Onatski's (2009) static and dynamic test of the null that the number of factors driving interest rate changes is one vs. the alternative that there are at least two factors. 

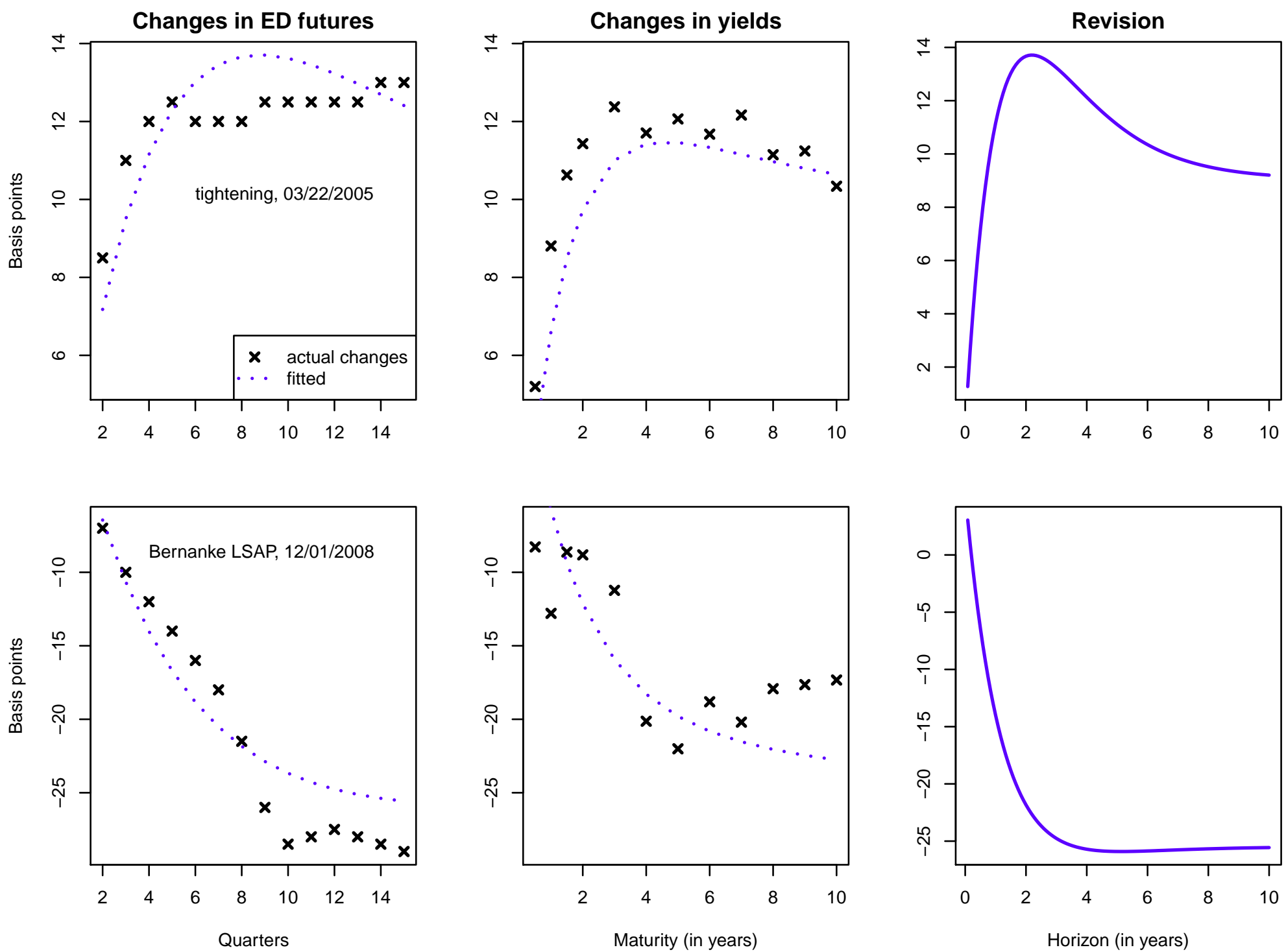

Notes: Actual changes (crosses) and model-implied changes (dashed lines) for Eurodollar futures (left column) and yields (middle column), as well as revision (right column) on two different days with policy actions. The top row shows changes for 22 March 2005 , the bottom row for 1 December 2008. 
Figure 2: Kuttner regressions

ED futures

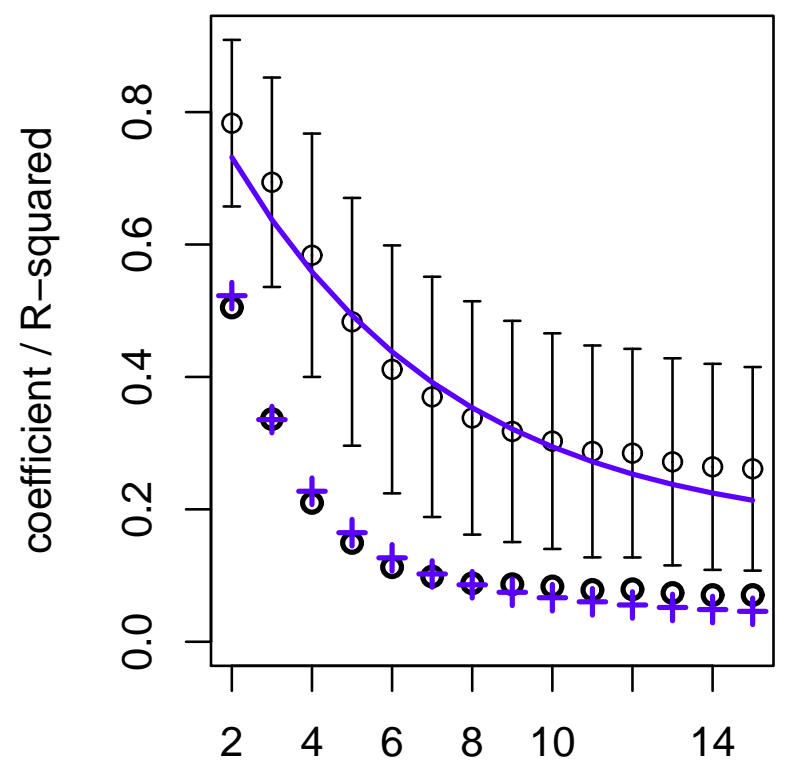

Quarters
Yields

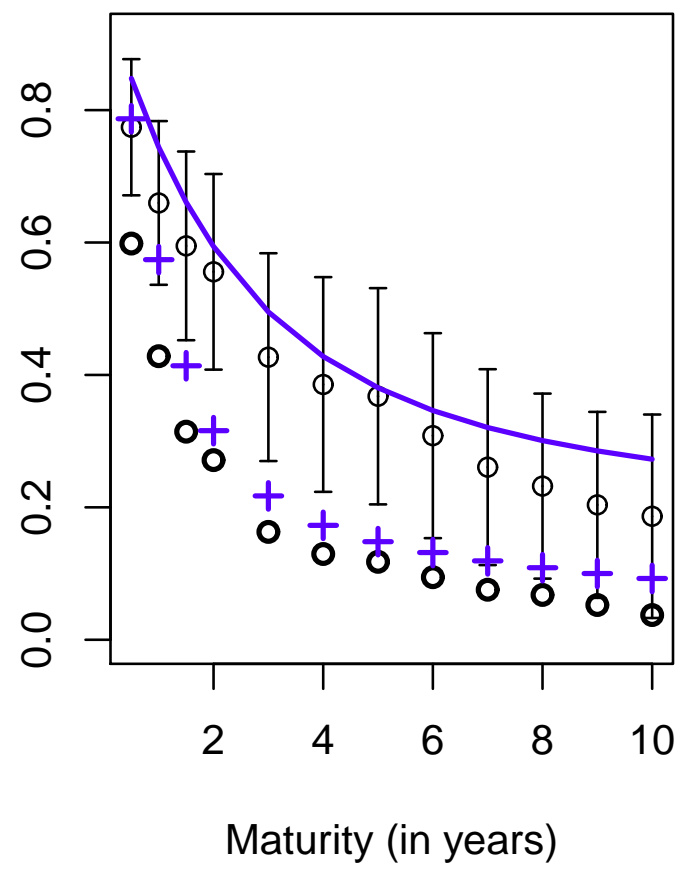

Notes: Actual and model-implied results for Kuttner regressions. The independent variable is the change in the one-month-ahead fed funds futures contract. The dependent variable is the change in a Eurodollar futures rate (left panel) or in a Treasury yield (right panel). Error bars show point estimates and 95\%-confidence intervals for the regression coefficients, solid lines show the model-implied coefficients. Circles show actual $R^{2}$ and crosses show model-implied $R^{2}$. The sample consists of 134 days with policy announcements but without employment reports, CPI/PPI releases or retail sales numbers, from 1990 to 2009. 
Figure 3: News-specific term structures of volatilities
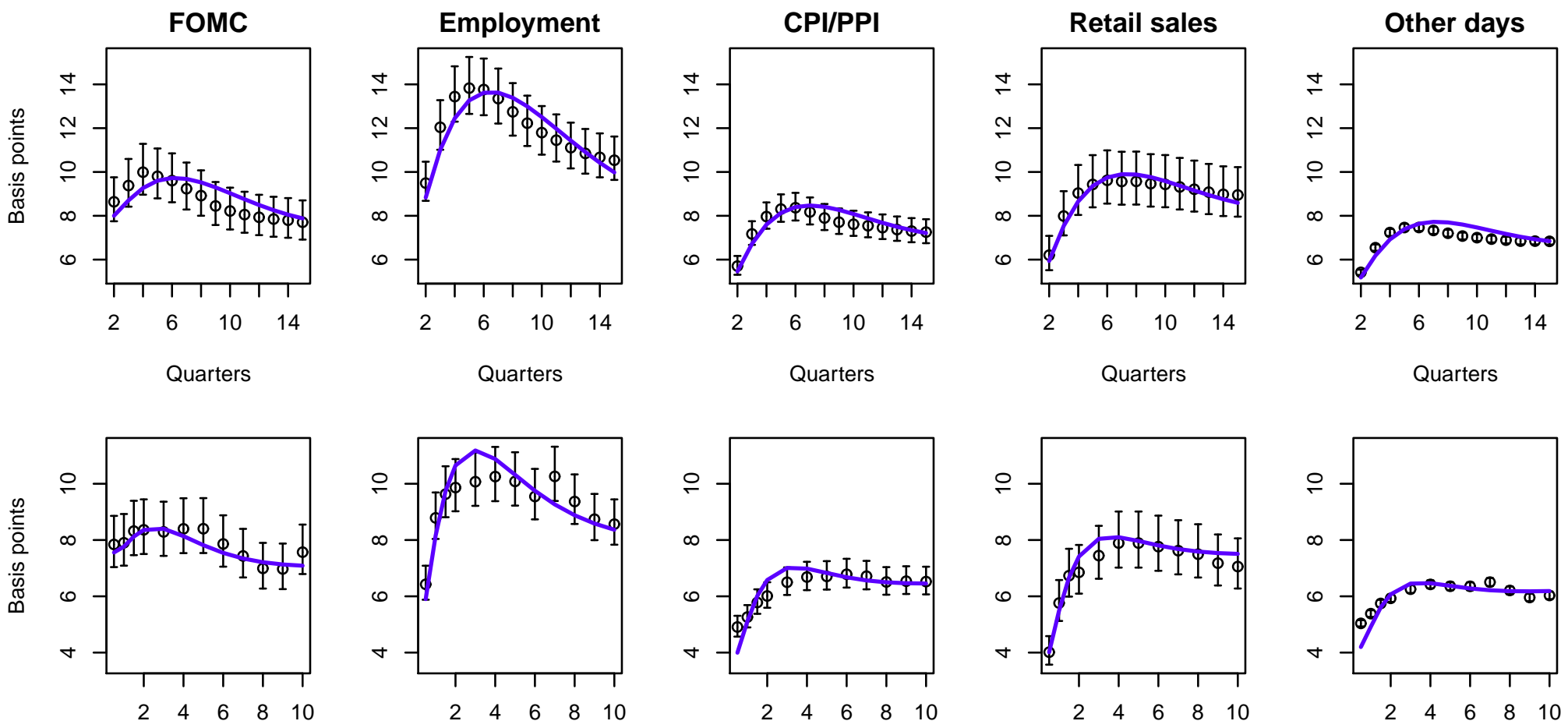

Maturity (in years)

Maturity (in years)

Maturity (in years)
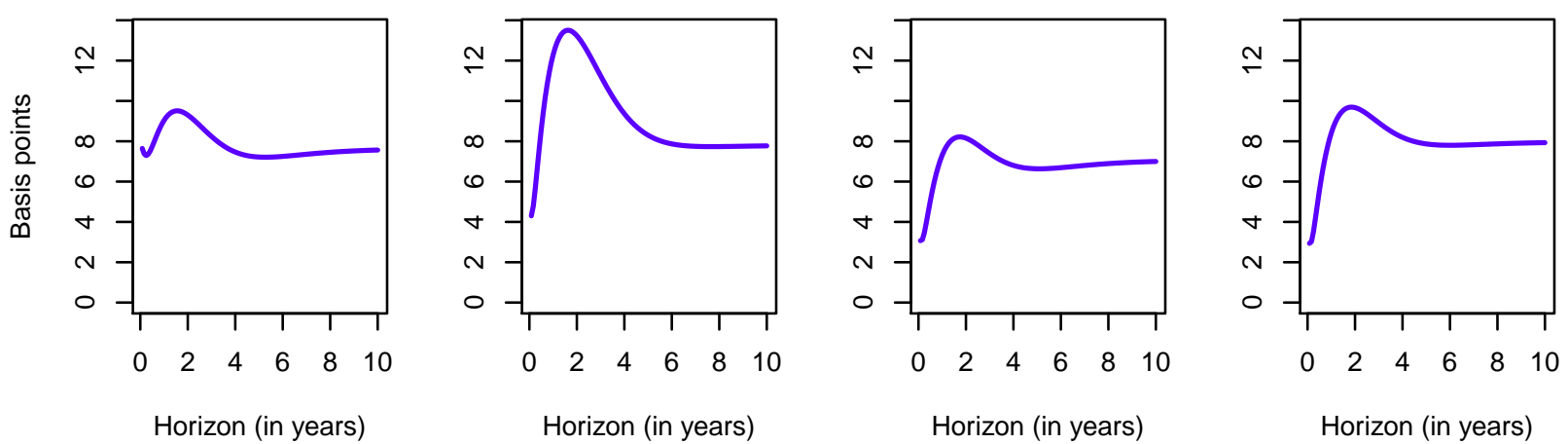

Maturity (in years)

Empirical volatilities (sample standard deviations) with 95\%-confidence intervals as well as model-implied volatilities for daily changes in Eurodollar futures rates (top row) and yields (middle row), as well as model-implied volatilities of short-rate expectations (bottom row) in each of the five news regimes. 
Figure 4: Selected macro surprises
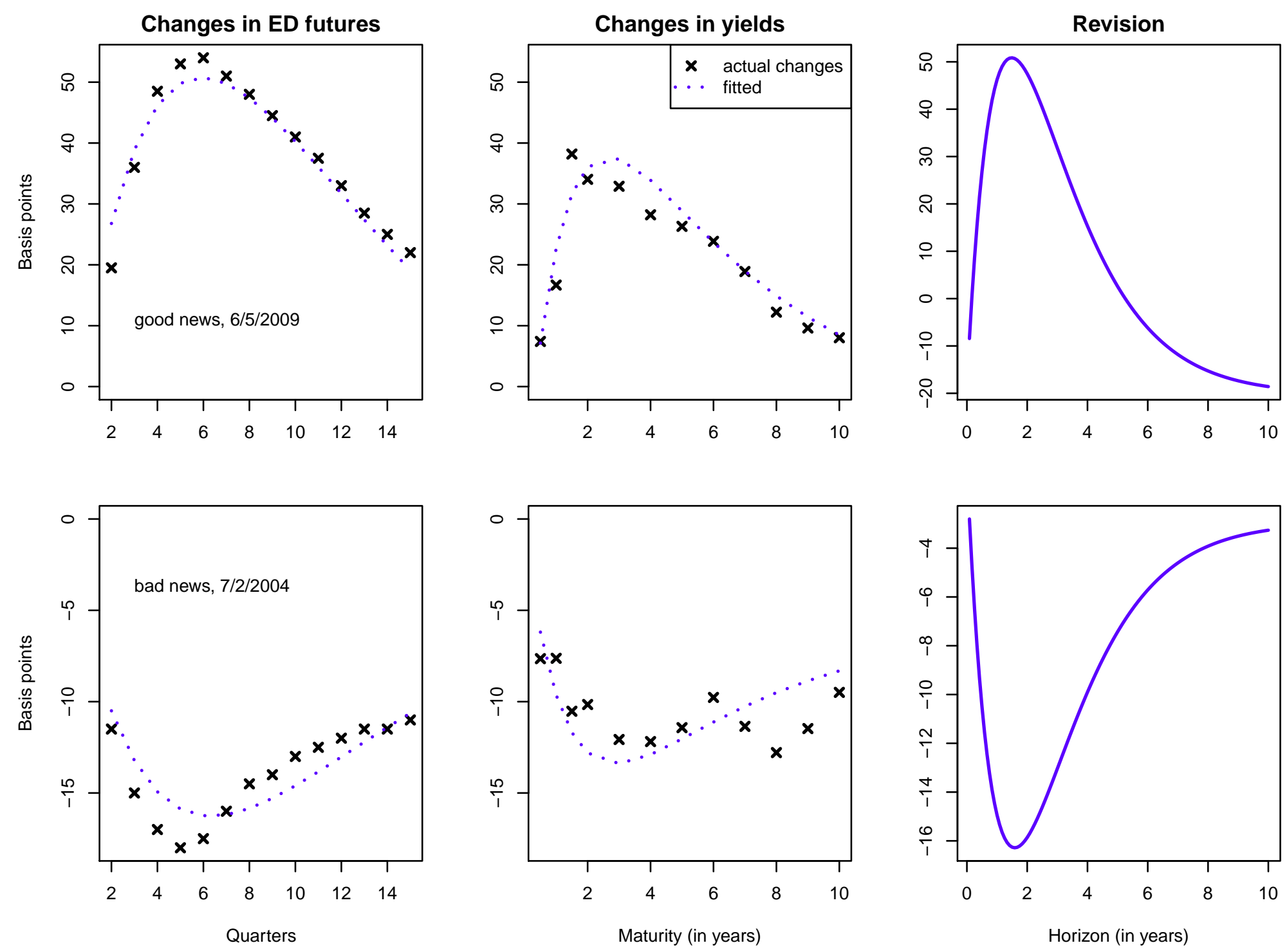

Notes: Actual changes (crosses) and model-implied changes (dashed line) for Eurodollar futures (left column) and yields (middle column), as well as revision (right column) on two different days with macro surprises. The top row shows changes for 5 June 2009 , when nonfarm payrolls of $-345,000$ exceeded expectations of $-500,000$. The bottom row shows changes for 2 July 2004, when nonfarm payrolls of 112,000 fell short of expectations of 230,000. 
Figure 5: Impact of macro surprises on Eurodollar futures
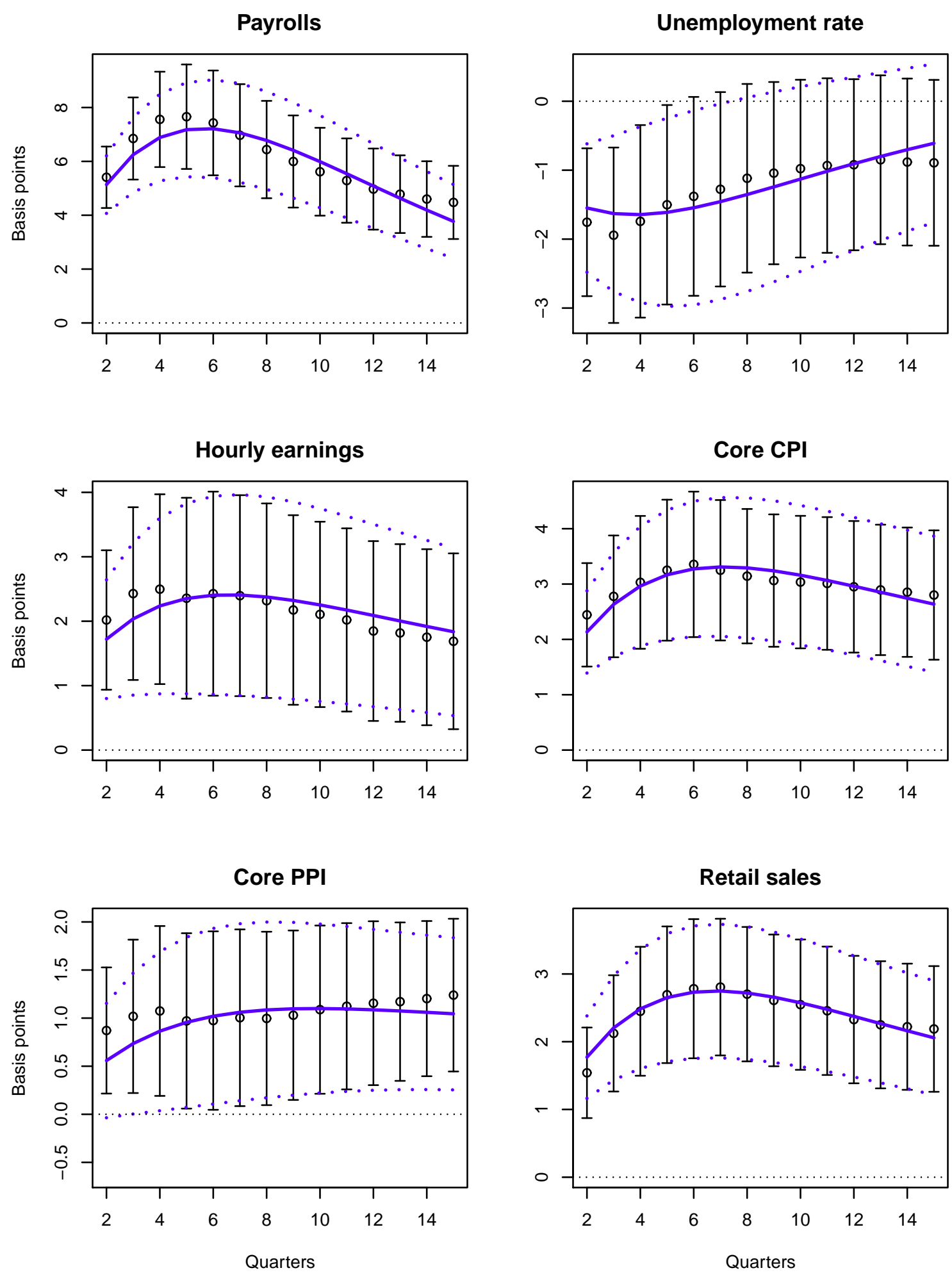

Notes: Actual (error bars) and model-implied (solid lines) responses in basis points for Eurodollar futures to macroeconomic data surprises, with $95 \%$-confidence intervals based on White standard errors. Coefficients capture the response to a one standard deviation surprise in each release. 
Figure 6: Impact of macro surprises on risk-neutral policy expectations
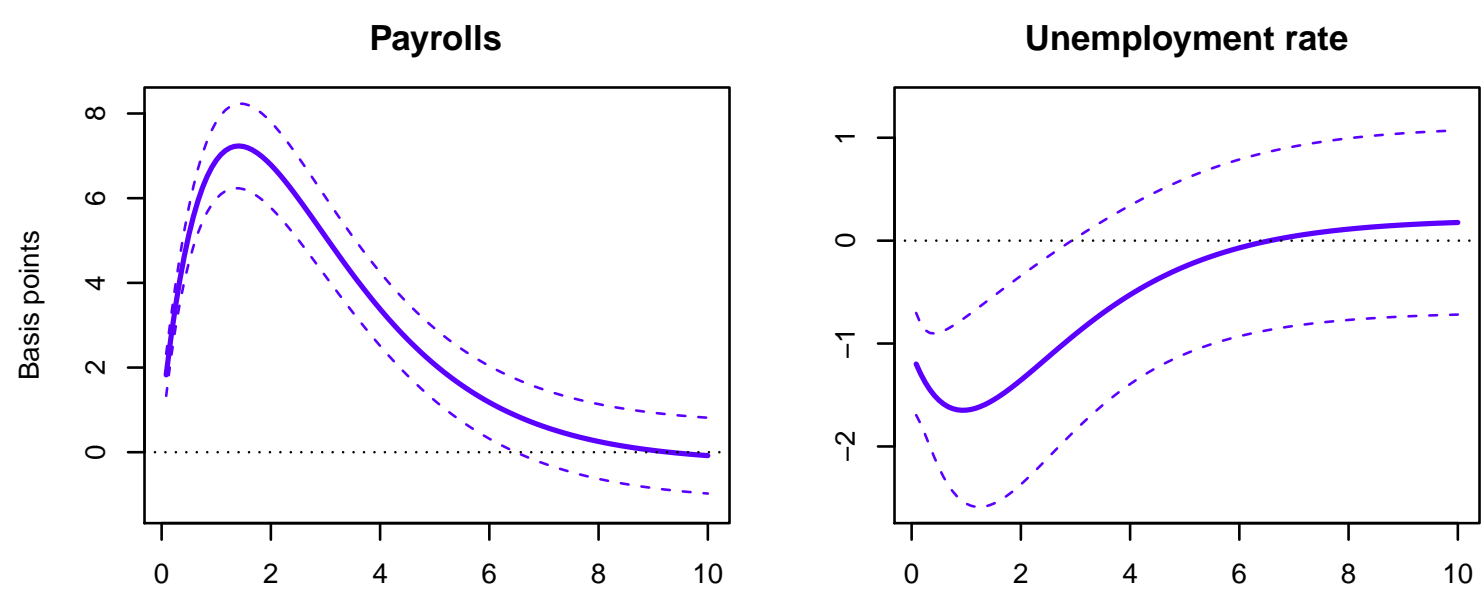

Hourly earnings
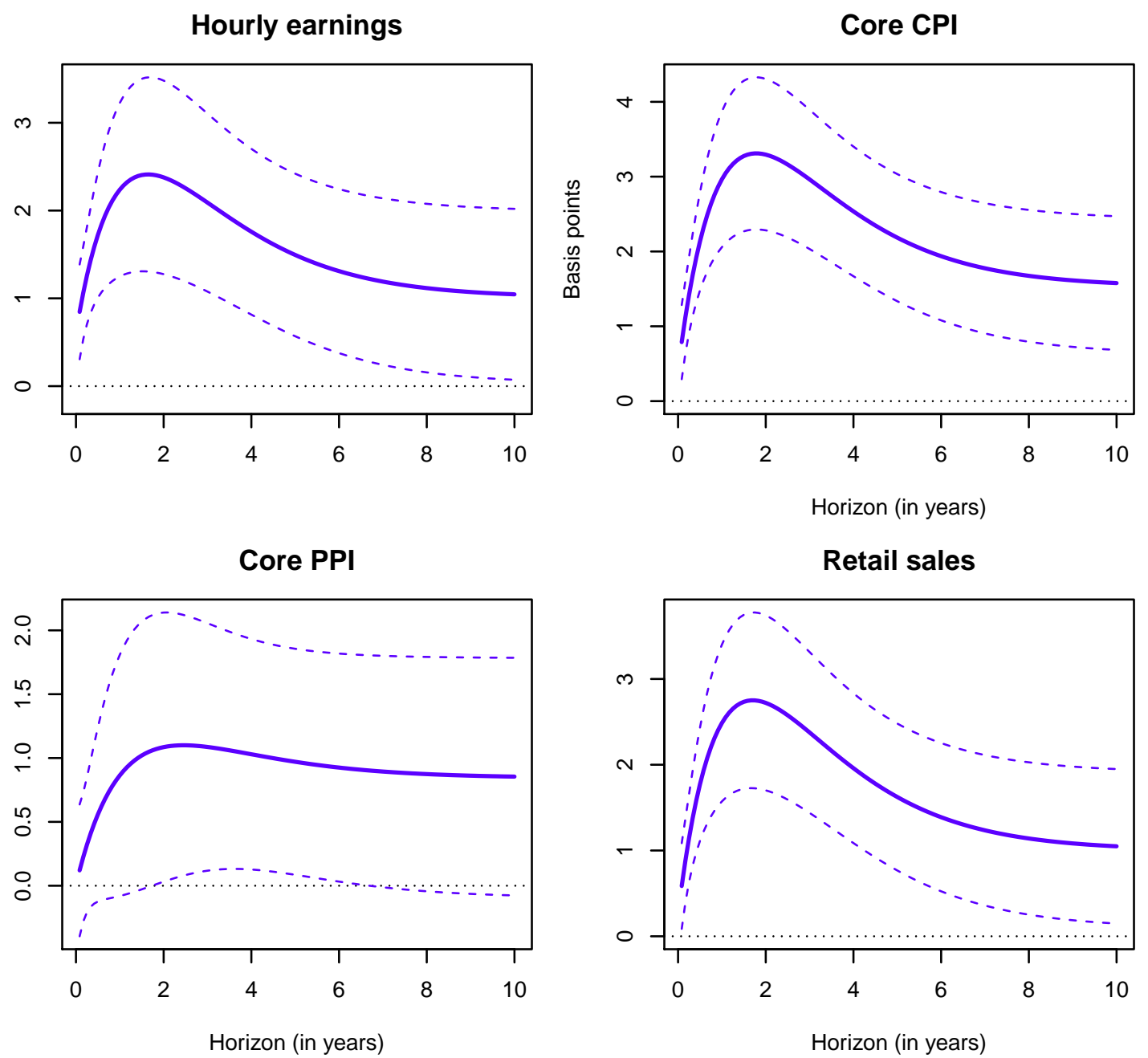

Notes: Model-implied responses (in basis points) of risk-neutral short-rate expectations to macroeconomic data surprises, with 95\%-confidence intervals based on White standard errors. Also shown is the long-run response. Coefficients capture the response to a one standard deviation surprise in each release. 
Figure 7: Impact of payroll surprises on actual and fitted forward rates

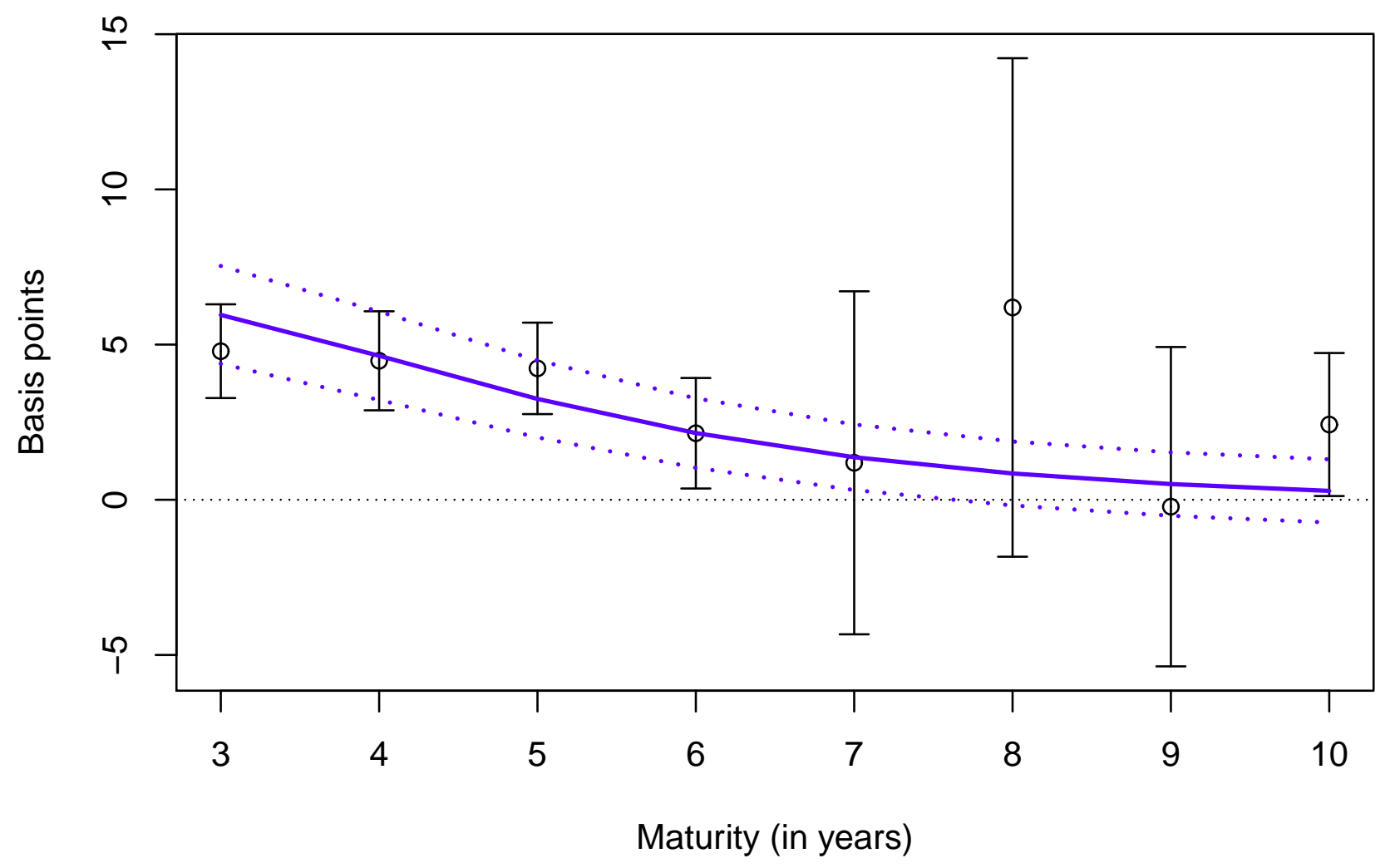

Notes: Responses (in basis points) of actual and fitted one-year forward rates to a one-standard-deviation surprise in non-farm payrolls, with 95\%-confidence intervals based on White standard errors. 